OPEN ACCESS

Edited by:

John D. Wade,

University of Melbourne, Australia

Reviewed by:

Ralf Hoffmann,

Leipzig University, Germany

Sander Izaak Van Kasteren,

Leiden University, Netherlands

${ }^{*}$ Correspondence:

April M. Kloxin

akloxin@udel.edu

Catherine L. Grimes

cgrimes@udel.edu

${ }^{+}$These authors have contributed equally to this work and share senior authorship

Specialty section:

This article was submitted to

Chemical Biology,

a section of the journal

Frontiers in Chemistry

Received: 23 December 2021

Accepted: 27 January 2022

Published: 15 February 2022

Citation:

Wodzanowski KA, Caplan JL, Kloxin AM and Grimes CL (2022) Multiscale Invasion Assay for Probing Macrophage Response to Gram-

Negative Bacteria.

Front. Chem. 10:842602.

doi: 10.3389/fchem.2022.842602

\section{Multiscale Invasion Assay for Probing Macrophage Response to Gram-Negative Bacteria}

\author{
Kimberly A. Wodzanowski ${ }^{1}$, Jeffrey L. Caplan ${ }^{2,3}$, April M. Kloxin $^{4,5 * t}$ and \\ Catherine L. Grimes ${ }^{1,2 * t}$
}

${ }^{1}$ Department of Chemistry and Biochemistry, University of Delaware, Newark, DE, United States, ${ }^{2}$ Department of Biological Sciences, University of Delaware, Newark, DE, United States, ${ }^{3}$ Bioimaging Center, Delaware Biotechnology Institute, Newark, DE, United States, ${ }^{4}$ Department of Chemical and Biomolecular Engineering, University of Delaware, Newark, DE, United States,

${ }^{5}$ Department of Materials Science and Engineering, University of Delaware, Newark, DE, United States

The immune system is a complex network of various cellular components that must differentiate between pathogenic bacteria and the commensal bacteria of the human microbiome, where misrecognition is linked to inflammatory disorders. Fragments of bacterial cell wall peptidoglycan bind to pattern recognition receptors within macrophages, leading to immune activation. To study this complex process, a methodology to remodel and label the bacterial cell wall of two different species of bacteria was established using copper (I) catalyzed azide-alkyne cycloaddition (CuAAC) and strain-promoted azide-alkyne cycloaddition (SPAAC). Additionally, an approach for three-dimensional (3D) culture of human macrophages and their invasion with relevant bacteria in a well-defined hydrogel-based synthetic matrix inspired by the microenvironment of the gut was established. Workflows were developed for human monocyte encapsulation and differentiation into macrophages in 3D culture with high viability. Bacteria invaded into macrophages permitted in situ peptidoglycan labeling. Macrophages exhibited biologically-relevant cytokine release in response to bacteria. This molecularly engineered, multi-dimensional bacteria-macrophage co-culture system will prove useful in future studies to observe immunostimulatory, bacterial fragment production and localization in the cell at the carbohydrate level for insights into how the immune system properly senses bacteria.

Keywords: biomaterials, bioorthogonal chemistry, invasion model, bacteria-macrophage interactions, click chemistry, live cell imaging, 3D cell culture, synthetic extracellular matrix

\section{INTRODUCTION}

The innate immune system is the body's first line of defense against invading pathogens. It is armed with sophisticated molecular mechanisms to sense and differentiate between pathogenic bacteria and the over 39 trillion bacteria constituting the human microbiome. Macrophages have many roles in the innate immune system, including ingesting pathogens by phagocytosis, scavenging dead cells and cell debris, and remodeling tissues after injury (Galli et al., 2011). Based on their tissue location and specialization in various microenvironments, macrophages take on a variety of names including alveolar macrophages (lung), microglia (brain and central nervous system), osteoclasts (bone), and Kupffer cells (liver) to name a few (Italiani and Boraschi, 2014). Macrophages are derived from monocytes, which circulate in the blood stream until entering the tissue and differentiating into 


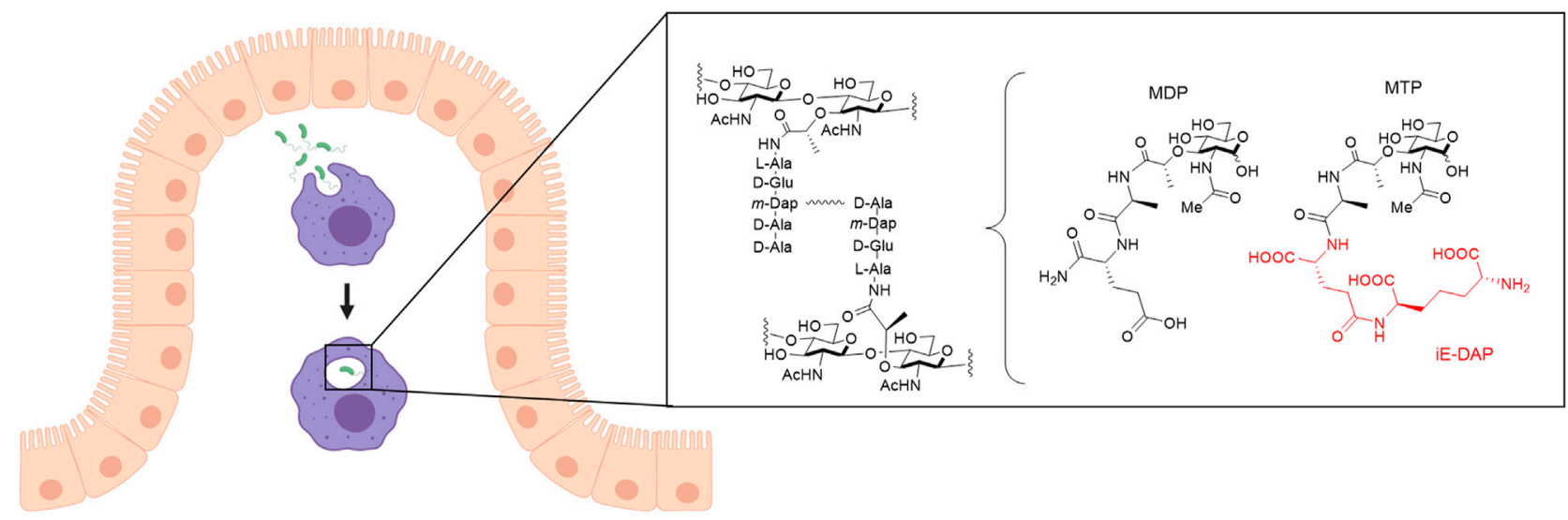

FIGURE 1 | Invasion of bacteria into macrophages. Macrophages (purple) that arise from monocytes reside in the connective tissue underlying the intestinal epithelium (beige). Macrophages phagocytose pathogens such as bacteria (green) and break them down into smaller fragments to determine what type of signaling for an immune response is needed. One recognition element of bacteria, peptidoglycan (PG), is composed of alternating $N$-acetyl glucosamine (NAG) and $N$-acetyl muramic acid (NAM) sugars with a pentapeptide chain off the 3-position of the NAM that is further crosslinked to form mature PG. Out of this larger structure, smaller synthetic fragments, muramyl dipeptide (MDP) and muramyl tripeptide (MTP), can be teased out with the core NAM sugar, which are known to elicit an immune response. D-glutamyl-meso-diaminopimelic acid (iE-DAP), shown in red, is a specific muropeptide in Gram-negative bacteria that activates the NLR, NOD1, to initiate an immune response. Figure created with Biorender.

macrophages, based on release of activating lymphokines from $\mathrm{T}$ lymphocytes present in the area of infection (Johnston, 1988). Mature macrophages express receptors that identify pathogens, allowing their proper uptake into the cell for degradation and response (Galli et al., 2011). These receptors include membraneassociated Toll-like receptors (TLRs) and cytosolic NOD-like receptors (NLRs), which are known to bind to fragments of the bacterial peptidoglycan (PG), a component of the bacterial cell wall. Peptidoglycan structure generally contains alternating sugars $N$-acetyl glucosamine (NAG) and $N$-acetyl muramic acid (NAM) with a pentapeptide chain off of the NAM sugar (Figure 1). Chemists have developed synthetic PG mimics of smaller fragments such as muramyl dipeptide (MDP) and muramyl tripeptide (MTP), which bind to NLRs and therefore have been used to study immune responses (Figure 1). Misrecognition of various PG fragments by the immune system is hypothesized to lead to diseases including Crohn's disease, inflammatory bowel disease, asthma, and gastrointestinal cancers (Geddes et al., 2009; Thaiss et al., 2016). Although MDP and MTP serve as important tools in studying immune responses in humans, the true identity of naturally produced immunostimulatory fragments, how they are generated, and how they interact with innate immune receptors in macrophages is not well known (Hasegawa et al., 2006; Herskovits et al., 2007; Humann and Lenz, 2009). Recently, underlying inflammation has been suggested to have other fundamental roles in biology that have yet to be discovered (Medzhitov, 2021). Therefore, there is a need for development of physiologically-relevant co-culture systems to model invasion of bacteria within human macrophages and begin probing these complex interactions toward addressing these important questions. Moreover, these systems should be amenable to downstream chemical biology labeling techniques of both the host and invading bacterial species.
In a typical experiment to study macrophage-bacteria interactions, macrophages are cultured on two-dimensional (2D) surfaces such as tissue culture polystyrene (TCPS). While this approach provides a well-defined environment, the material is unnaturally polarizing and has mechanical properties (Young's modulus $(\mathrm{E}) \sim 3 \mathrm{GPa}$ ) a million times stiffer than those of the native soft tissue of the intestines $(\mathrm{E} \sim 2-20 \mathrm{kPa}$ ) (SimonAssmann et al., 1995; Rehmann and Kloxin, 2013). Seminal works have demonstrated how the function of many different cell types (e.g., stem cells, epithelial cells, cancer cells) is influenced by the dimensionality and stiffness of the culture environment (Petersen et al., 1992; Tanaka et al., 2004; Engler et al., 2006). Soft three-dimensional (3D) culture systems have been shown to be particularly effective for probing cell differentiation and migration in a physiologically relevant manner (Tibbitt and Anseth, 2009). As macrophages reside within connective tissue underneath the epithelium in the gut and respond to bacteria that breach this layer, 3D migration and interactions with the extracellular matrix (ECM) play an important role in infection clearing, suggesting the potential importance of studying macrophage response to bacterial invasion in multi-dimensional systems (Wodzanowski et al., 2020).

For studies of the gut in $3 \mathrm{D}$, recent progress has been made in the development of organoids cultures, amongst other approaches (Snyder et al., 2020; Wodzanowski et al., 2020). Organoids are 3D cell clusters formed in vitro, with stem cells or cells derived from primary tissues, and are capable of selforganization and self-renewal, exhibiting similar function to in vivo organs (de Souza, 2018). However, organoids lack immune cells, in addition to requiring lengthy timescales with intensive maintenance to fully generate (e.g., 1-3 months) (Clevers, 2016; de Souza, 2018). Animal models have also provided insights in the context of inflammatory bowel disorders (IBD) by allowing study 
of mucosal inflammation. However, these models can have reproducibility issues and do not sufficiently capture human IBD as they cannot accurately control for intestinal pathology, inflammation, and bacteria related to IBD (Blumberg et al., 1999; Goyal et al., 2014; Webb, 2014; Wodzanowski et al., 2020). Currently, a gap remains in physiologically-relevant, multidimensional systems for studying specific bacteria-immune cell interactions, where few immune cells, particularly macrophages, have been cultured in three dimensions (Sun et al., 2011; Blasioli et al., 2014; Peck et al., 2014; Samavedi et al., 2017). There is a need for robust hybrid systems with well-defined 3D properties that can be manipulated to reflect aspects of the native tissue and are suitable for co-culture of macrophages and bacteria.

Hydrogels, crosslinked water-swollen networks of hydrophilic polymers, have emerged as good candidates for mimicking a variety of soft tissue microenvironments for $3 \mathrm{D}$ cell culture applications. In particular, synthetic hydrogels can be engineered to mimic key properties of the native ECM, including mechanical properties and biochemical content, and permit $3 \mathrm{D}$ cell encapsulation and culture (Caliari and Burdick, 2016). These systems include multi-arm polymers (e.g., biologically-inert poly (ethylene glycol) (PEG)) that have been functionalized with reactive handles (e.g., (meth)acrylates, norbornenes, vinyl sulfones, thiols) for crosslinking with functionalized cell-degradable and integrin-binding peptides inspired by native tissues for a range of applications (Caliari and Burdick, 2016). Studies of macrophages with such synthetic materials often have focused on probing the foreign body response in 2D culture studies (Blakney et al., 2012; Witherel et al., 2019), given its importance in the design of implanted materials, with recent efforts demonstrating feasibility of macrophage 3D culture (Samavedi et al., 2017; Kim et al., 2019). More recently, matrix-metalloproteinase (MMP) degradable synthetic hydrogels have been utilized to encapsulate human epithelial-mesenchymal intestinal organoids for coculture studies (Jowett et al., 2021). Additionally, 3D cocultures are beginning to be developed to study bacterial infections such as the case of the oral microbiome and the lung (Montefusco-Pereira et al., 2020; Mountcastle et al., 2020). These versatile materials provide significant opportunities for creating multi-dimensional culture systems with well-defined and tunable properties for probing macrophage-bacteria interactions to test hypotheses in more physiologically-relevant environments related to the gut.

In parallel, novel methods have emerged to study the bacterial cell wall. Work has been done previously to label various aspects of PG including small fluorophores coupled to D-amino acids, NAG and NAM sugar probes, and near-infrared radiation (NIR) fluorogenic probes (Wodzanowski et al., 2020; Banahene et al., 2021). Because synthetic fragments MDP and MTP both contain the NAM sugar, it is believed that NAM plays an important structural role in fragment identification and subsequent infection clearing by macrophages. NAM probes developed have had a variety of functional groups including bioorthogonal handles, fluorescent dyes, biotin, and photoactivatable crosslinker (DeMeester et al., 2018). Of particular interest are the click handles, especially the bioorthogonal azide at the 2-acetyl position, providing versatility in what is 'clicked' onto the handle for various assays (Liang et al., 2017; DeMeester et al., 2019). Another advantage of the NAM probes is that under a lethal dose of the antibiotic fosfomycin, the first enzyme in the PG biosynthetic pathway, Mur A, can be selectively inhibited, which prevents first committed PG biosynthetic pathway steps from occurring, and cells only survive if they uptake supplemented NAM sugar provided through alternative recycling machinery if present in the cell (Kahan et al., 1974). Instrumental work by Mayer and coworkers showed that certain Pseudomonas species contain recycling machinery involving the enzymes anomeric NAM/ NAG kinase (AmgK) and $\alpha$-1-phosphate uridylyl transferase (MurU) that under a lethal dose of Fosfomycin can recycle NAM into uridine diphosphate (UDP)-NAM, which is then incorporated into mature PG (Gisin et al., 2013). Therefore, utilizing these NAM probes can allow visualization of the bacterial PG core and have potential downstream applications as an affinity handle for purifying naturally produced PG fragments from breakdown in macrophages.

In this work, we aimed to establish a well-defined, bio-inspired coculture system that enabled encapsulation and culture of immune cells relevant to the human gut, and to study their response to invasion by Gram-negative bacteria in three dimensions. First, we utilized the biorthogonal azide NAM probe to remodel and label bacterial PG, including for the first time the pathogen $P$. aeruginosa, through copper (I) azide alkyne cycloaddition (CuAAC) and strainpromoted azide-alkyne cycloaddition (SPAAC) click reactions. Next, we developed a PEG-peptide hydrogel composition inspired by aspects of the microenvironment of the healthy gut. We established workflows for the successful encapsulation of human monocytes and their differentiation into human macrophages within these hydrogel-based synthetic matrices where cells can be facilely recovered by digestion of the hydrogel with collagenase for downstream assays. Utilizing the fluorescent bacteria, we visualized macrophage engulfment of bacteria in real time and in both $2 \mathrm{D}$ and $3 \mathrm{D}$ culture. Further, we probed macrophage cytokine expression in these systems with contrasting dimensionality, elucidating key differences in macrophage response. These studies provide new tools, such as an expansion of previous fluorescent labeling strategies of bacteria and a new 3D model system, for insights into the interactions between bacteria and immune cells and how our immune system recognizes bacteria in a variety of physiologically relevant settings.

\section{MATERIALS AND METHODS}

See supplemental information (SI) for general materials and methods.

\section{Bacterial Labeling and Remodeling With SPAAC}

Overnight pre-cultured E. coli $\triangle M u r Q-K U$ cells (Liang et al., 2017) or $P$. aeruginosa were inoculated into fresh LB medium and were incubated until the $\mathrm{OD}_{600 \mathrm{~nm}}$ was about $0.600 .1 .2 \mathrm{ml}$ of cell 
suspension were collected by centrifugation at $8,000 \mathrm{rpm}$ $(6,000 \mathrm{~g})$ for $5 \mathrm{~min}$. E. coli $\triangle \mathrm{MurQ}-K U$ cells were resuspended in $190 \mu \mathrm{LB}$ medium. $6 \mathrm{mM}$ NAM sugar (NAM (Sigma-Aldrich) or AzNAM (synthesized in house based on established protocols) (Liang et al., 2017)), $1 \mathrm{mM}$ isopropyl-1-thio- $\beta$-D-galactoside (E. coli only) and $200 \mu \mathrm{g} / \mathrm{ml}$ fosfomycin were added into cell samples. Cells were incubated while shaking at $37^{\circ} \mathrm{C}$ for $60 \mathrm{~min}$. Cells were then collected $(10,000 \mathrm{rpm}, 2 \mathrm{~min})$ and washed with $2 \times 600 \mu \mathrm{l} 1 \mathrm{xPBS}$. Cells were resuspended in $194 \mu \mathrm{LB}$ and then $30 \mu \mathrm{M}$ DBCO-488 (AZDye ${ }^{\mathrm{TM}} 488$ DBCO; Click Chemistry Tools) was added. Cells were covered and incubated at $37^{\circ} \mathrm{C}$ for $40 \mathrm{~min}$ while shaking. Cells were then collected $(10,000 \mathrm{rpm}, 2 \mathrm{~min})$ and washed with $2 \times 600 \mu \mathrm{l} 1 \mathrm{xPBS}$. Cells were fixed in $4 \%$ paraformaldehyde in PBS for $20 \mathrm{~min}$. Cells were washed with $2 \times 600 \mu \mathrm{l} 1 \mathrm{xPBS}$. Cells were washed $2 \times 600 \mu \mathrm{l} 1 \mathrm{xPBS}, 1 \times 200 \mu \mathrm{l}$ $1 \times$ PBS, $1 \times 200 \mu \mathrm{l} 1 \times$ PBS for $45 \mathrm{~min}$ in the dark, and $1 \times 200 \mu \mathrm{l}$ $1 \mathrm{xPBS}$. The cells were resuspended in $100 \mu \mathrm{l} 1 \mathrm{xPBS}$. $15 \mu \mathrm{l}$ of cells were added to pre-treated coverslips for confocal microscopy. The rest of the cells were stored at $4^{\circ} \mathrm{C}$ until flow cytometry analysis.

\section{Bacterial Labeling and Remodeling With CuAAC}

Bacterial remodeling and labeling was achieved based on established protocols for E. coli (Liang et al., 2017; DeMeester et al., 2019). Briefly, overnight pre-cultured E. coli $\triangle M u r Q-K U$ (EQKU) cells or $P$. aeruginosa were inoculated into fresh $\mathrm{LB}$ medium and were incubated until the $\mathrm{OD}_{600 \mathrm{~nm}}$ was about $0.600 .1 .2 \mathrm{ml}$ of cell suspension were collected by centrifugation at $8,000 \mathrm{rpm}(6,000 \mathrm{~g})$ for $5 \mathrm{~min}$. Cells were resuspended in $190 \mu \mathrm{LB}$ medium. $6 \mathrm{mM}$ NAM sugar 1 or 2 (NAM, AzNAM), $1 \mathrm{mM}$ isopropyl-1-thio- $\beta$ D-galactoside (E. coli only) and $200 \mu \mathrm{g} / \mathrm{ml}$ fosfomycin were added into cell samples. Cells were incubated while shaking at $37^{\circ} \mathrm{C}$ for $60 \mathrm{~min}$. Cells were then collected (10,000 rpm, $2 \mathrm{~min})$ and washed with $2 \times 600 \mu \mathrm{l} 1 \mathrm{xPBS}$. Cells were fixed in $4 \%$ paraformaldehyde in PBS for $20 \mathrm{~min}$. Cells were washed with $2 \times 600 \mu \mathrm{l} 1 \mathrm{xPBS}$. Cells were resuspended in $190 \mu \mathrm{l}$ PBS to prepare for the click reaction. To the bioorthogonally tagged bacterial cells was sequentially added $1 \mathrm{mM}$ $\mathrm{CuSO}_{4}$ solution, $140 \mu \mathrm{M}$ BTTAA, $1.2 \mathrm{mM}$ freshly prepared (+)-sodium (L) ascorbate (Sigma-Aldrich) and $20 \mu \mathrm{M}$ of Alk488. Cells were incubated at room temperature for $30 \mathrm{~min}$. Cells were washed $2 \times 600 \mu \mathrm{l} 1 \mathrm{xPBS}, 1 \times 200 \mu \mathrm{l} 1 \mathrm{xPBS}, 1 \times 200 \mu \mathrm{l} 1 \mathrm{xPBS}$ for $45 \mathrm{~min}$ in the dark, and $1 \times 200 \mu \mathrm{l} 1 \mathrm{xPBS}$. The cells were resuspended in $100 \mu \mathrm{l} 1 \mathrm{xPBS}$ and prepared for imaging.

\section{Flow Cytometry for Bacterial Labeling}

Flow cytometry was performed on ACEA Novocyte Flow Cytometer. Samples were briefly vortexed before each run. 100,000 cell counts were collected for each sample and were analyzed in triplicate, and fluorescence intensities (height) were generated and overlaid.

\section{Growth Curve Assay With Plate Reader}

Overnight pre-cultured E. coli $\triangle M u r Q-K U$ or P. aeruginosa cells were inoculated into fresh LB medium (supplemented with kanamycin and chloramphenicol for $E$. coli cells only) to an
$\mathrm{OD}_{600 \mathrm{~nm}}$ of approximately 0.200 . Cells were incubated at $37^{\circ} \mathrm{C}$ shaking for $\sim 1 \mathrm{~h} 1 \mathrm{ml}$ of cell suspension were added to new sterile Eppendorf tubes and spun at $8,000 \mathrm{rpm}$ for $5 \mathrm{~min}$ to pellet the cells. The cells were resuspended in $190 \mu \mathrm{l}$ of LB and supplemented with $200 \mu \mathrm{g} / \mathrm{ml}$ fosfomycin, $1 \mathrm{mM}$ IPTG for E. coli cells only, and $6 \mathrm{mM}$ NAM or AzNAM probe. The cells were then incubated for an additional hour to remodel. Then, the cells were pelleted to remove excess probe at 10,000 rpm for $2 \mathrm{~min}$ and resuspended in $100 \mu \mathrm{l}$ of fresh LB. $100 \mu \mathrm{l}$ of cell solution was added into each well of a white, clear bottom 96 well plate in triplicate for each probe concentration. $30 \mu \mathrm{l}$ of DBCO-488 was added to appropriate wells. The plate was incubated at $37^{\circ} \mathrm{C}$ in the plate reader where it was shaken for $2 \mathrm{~min}$, scanned at $600 \mathrm{~nm}$, and then repeated every $20 \mathrm{~min}$ for $6 \mathrm{~h}$ (Brown et al., 2021a). Cell growth curves were formulated with Origin 2019.

\section{Synthesis and Characterization of Norbornene-Functionalized PEG}

Multi-arm (Herskovits et al., 2007) PEG $\left(M_{n} \sim 40,000\right.$ g/mol) was functionalized with norbornene end groups according to established protocols (Rehmann et al., 2016; Ovadia et al., 2018). Briefly, in a $250 \mathrm{ml}$ round bottom flask, PEG-8$\mathrm{NH}_{2} \cdot \mathrm{HCl}$ (5 g, Jenkem) was dissolved in anhydrous $\mathrm{N}, \mathrm{N}$ dimethylformamide (DMF, ThermoFisher) and stirred at room temperature. In a second $250 \mathrm{ml}$ round bottom flask, 5norbornene-2-carboxylic acid (Nb-COOH) (17.6 M equivalent; 2.2 excess relative to amine groups on the PEG), 4methylmorpholine (4-MMP) (36 M equivalent), and HATU (16 M equivalent; 2 excess) were dissolved in $10 \mathrm{ml}$ of DMF stirring at room temperature. Once the individual flask components were dissolved, they were combined into one flask and stirred at room temperature overnight. The solution was then precipitated twice in cold diethyl ether $(500 \mathrm{ml}, 14 \mathrm{x}$ excess diethyl ether relative to DMF), and the resulting suspension was filtered with a Buchner funnel with filter paper to recover the precipitated polymer product. The solid PEG product was dried in the vacuum oven overnight. The PEG was purified by dialysis (MWCO $1000 \mathrm{~g} / \mathrm{mol}$, Spectrum Laboratories)) in $\mathrm{mqH}_{2} 0$ for $48 \mathrm{~h}$ according to manufacturer's instructions followed by freezing and lyophilization. Product purity was confirmed by ${ }^{1} \mathrm{H}$ NMR in DMSO- $\mathrm{d}_{6}$. Norbornene functionality was determined to be approximately $75 \%$ on average (Supplementary Figure S13), and PEG-8-Nb was stored at $-20^{\circ} \mathrm{C}$ following lyophilization.

\section{Synthesis and Characterization of Peptides}

All peptides were synthesized using solid phase peptide synthesis based on established protocols (Ovadia et al., 2018). The difunctional linker peptide (GCRDVPMSMRGGDRCG) and the monofunctional pendant peptide (CGKGYIGSR) were synthesized using standard FMOC-chemistry on an automated peptide synthesizer (PS3 Peptide Synthesizer; Protein Technologies, Inc, Tucson, AZ and Liberty Blue; CEM, Matthews, NC). The peptides were built on Rink Amide MBHA resin. All amino acids were double coupled. The peptides were cleaved from the resin for $2-3 \mathrm{~h}$ in $95 \%$ 
trifluoroacetic acid, 2.5\% water, and $2.5 \%$ triisopropylsilane supplemented with $50 \mathrm{mg} / \mathrm{ml}$ dithiothreitol. Following cleavage, all peptides were precipitated in cold diethyl ether at $4^{\circ} \mathrm{C}$ and let air dry overnight. The peptides were purified by reverse-phase high performance liquid chromatography (HPLC; XBridge BEH C18 OBD $5 \mu \mathrm{m}$ column; Waters, Milford, MA) with a linear $95 \% / 5$ to $5 \% / 95 \%$ linear water-acetonitrile (ACN) gradient over 15-30 min. Purified peptides were subsequently lyophilized. Their molecular weights were verified by mass spectrometry (Supplementary Figure S11, Supplementary Figure S12), and the thiol concentration of each peptide upon reconstitution for stock solution preparation was determined using Ellman's assay. Purified peptides were dissolved in phosphate buffered saline (PBS) and stored at $-80^{\circ} \mathrm{C}$.

\section{Synthesis and Rheological Characterization of Hydrogels}

Monomer stocks were prepared by dissolving each component in sterile phosphate buffered saline (PBS): PEG-8-Nb (40 mM Nb functionality); lithium phenyl-2,4,6trimethylbenxoylphospohinate (LAP) $(30 \mathrm{mM})$ sterile filtered with $0.2 \mu \mathrm{M}$ filter; and each peptide $(\sim 200 \mathrm{mM})$. PEG-8-Nb and LAP stocks were stored at $-20^{\circ} \mathrm{C}$, and peptide stocks were stored at $-80^{\circ} \mathrm{C}$.

A bulk hydrogel precursor solution was prepared using $7 \mathrm{mM}$ PEG-8-Nb, $5 \mathrm{mM}$ peptide crosslinker, $2 \mathrm{mM}$ pendant peptide, and $2 \mathrm{mM}$ LAP in PBS. Rheology measurements were conducted as previously reported (Italiani and Boraschi, 2014) on AR-G2 rheometer with UV-visible light attachment (TA instruments) in tandem with an Omnicure Series 2000 light source (Excelitas) with a $365 \mathrm{~nm}$ bandpass filter and light guide (Exfo). Briefly, $10 \mu \mathrm{l}$ of hydrogel precursor solution was pipetted onto the quartz plate of the UV-vis light attachment on the rheometer with a $8 \mathrm{~mm}$ flat plate geometry installed, and the gap was set to $150 \mu \mathrm{m}$. Hydrogel crosslinking and gelation were monitored by measuring storage $\left(G^{\prime}\right)$ and loss $\left(G^{\prime \prime}\right)$ moduli at $0.5 \%$ applied strain and $2 \mathrm{rad} / \mathrm{s}$ frequency upon irradiation $\left(10 \mathrm{~mW} / \mathrm{cm}^{2}\right.$ at $\left.365 \mathrm{~nm}\right)$. The gelation time was determined to be less than $2 \mathrm{~min}$ based on the change in G' being within $5 \%$ between two consecutive points (Geddes et al., 2009). Frequency sweeps at 1\% strain were performed after the irradiation was complete to measure the final moduli of hydrogels formed in situ. All of the rheometric measurements were performed within the linear viscoelastic regime. Final equilibrium swollen moduli at physiological temperature were calculated as previously reported (Johnston, 1988; Thaiss et al., 2016) using the in situ measured modulus and the following equations:

$$
\begin{gathered}
G_{\text {final }}=G_{0}\left(\frac{T_{\text {final }}}{T_{0}}\right)\left(\frac{Q_{\text {final }}}{Q_{0}}\right)^{-\frac{1}{3}} \\
Q_{\text {final }}=(1-2 \chi) N^{0.57} \phi^{-0.38}
\end{gathered}
$$

where $G_{0}$ is the in situ measured shear modulus; $T_{\text {final }}$ is $310 \mathrm{~K} ; \mathrm{T}_{0}$ is $298 \mathrm{~K} ; \mathrm{Q}_{0}$ is the initial volumetric swelling ratio of the hydrogels; $\chi$ is 0.426 , the PEG-water interaction parameter; $\mathrm{N}$ is 304, the number of PEG repeats between crosslinks; and $\phi$ is the initial volume fraction of polymer. Lastly, the Young's modulus (E) was estimated by rubber elasticity theory:

$$
E=2 G_{\text {final }}(1+v)
$$

where $\nu$ is Poisson's ratio and is taken to be 0.5 for these incompressible, elastic PEG hydrogels.

\section{Mammalian Cell Culture}

THP-1, HEK293T, and CCL151 cells were purchased from the American Type Culture Collection (ATCC) and cultured under sterile conditions at $37^{\circ} \mathrm{C}$ with $5 \% \mathrm{CO}_{2}$. THP1 cells were grown in RPMI media; HEK293T cells were grown in DMEM media; and CCL151 cells were grown in F12K media. All media was supplemented with $10 \%$ FBS (Atlantic Biologicals), $2 \mathrm{mM}$ L-glutamine, and $2 \mathrm{mM}$ penicillin-streptomycin. THP-1 cells were stimulated with $200 \mathrm{nM}$ PMA for $72 \mathrm{~h}$ to differentiate into macrophages (Zhang et al., 2008; Daigneault et al., 2010; Lund et al., 2016).

\section{Cell Encapsulation}

THP-1 cells were encapsulated as a single cell suspension at a density of $5 \times 10^{6}$ cells per $\mathrm{ml}$ in $20 \mu \mathrm{l}$ of hydrogel precursor solution $(250,000$ cells/hydrogel). Precursor solution was prepared using $7 \mathrm{mM}$ PEG-8-Nb, $5 \mathrm{mM}$ linker peptide, $2 \mathrm{mM}$ pendant peptide, $2 \mathrm{mM}$ lithium phenyl-2,4,6trimethylbenzoylphosphinate (LAP), and THP-1 cell suspension in PBS, where all concentrations noted are for the functional handle. Hydrogels were formed in $10 \mathrm{~mm} \times 0.5 \mathrm{~mm}$ sterile gasket molds unless otherwise noted $(43 \mu \mathrm{l}$ precursor solution/mold) upon irradiation with a cytocompatible dose of long wavelength UV light $\left(10 \mathrm{~mW} / \mathrm{cm}^{2}, 365 \mathrm{~nm}, 2 \mathrm{~min}\right.$; Omnicure 2000 with light guide and collimating lens). Two replicates were formed at a time and then placed in a 24 well plate with $500 \mu \mathrm{l}$ of RPMI media. $200 \mathrm{nM}$ PMA was added to the media in each well for differentiation into macrophages. Cellhydrogel constructs were incubated under sterile conditions at $37^{\circ} \mathrm{C}$ with $5 \% \mathrm{CO}_{2}$.

\section{Live/Dead Viability Assay on Encapsulated Cells}

THP-1 monocyte and macrophage cell viability following encapsulation in the hydrogels was assessed on days 1, 3, and 7 using a LIVE/DEAD ${ }^{\circledast}$ Viability/Cytotoxicity Kit (ThermoFisher Scientific). THP-1 monocytes were encapsulated as a single cell suspension at a density of $5 \times 10^{6}$ cells per $\mathrm{ml}$ in $20 \mu \mathrm{l}$ of hydrogel precursor solution $(250,000$ cells/hydrogel). Precursor solution was prepared using $7 \mathrm{mM}$ PEG-8-Nb, $5 \mathrm{mM}$ linker peptide, $2 \mathrm{mM}$ pendant peptide, $2 \mathrm{mM}$ LAP, and THP-1 cell suspension in PBS. Hydrogels were formed in $10 \mathrm{~mm} \times$ $0.5 \mathrm{~mm}$ sterile gasket molds $(43 \mu \mathrm{l}$ precursor solution/mold) upon irradiation with a cytocompatible dose of long wavelength UV light $\left(10 \mathrm{~mW} / \mathrm{cm}^{2}, 365 \mathrm{~nm}, 2 \mathrm{~min}\right.$; Omnicure 2000 with light guide and collimating lens). Two replicates were formed at a time and then placed in a 24 well plate with $500 \mu \mathrm{l}$ of RPMI media. $200 \mathrm{nM}$ TPA was added to the media in each well 
for differentiation into macrophages. Cell-hydrogel constructs were incubated under sterile conditions at $37^{\circ} \mathrm{C}$ with $5 \% \mathrm{CO}_{2}$. Hydrogels $(n=3)$ were removed from incubator on days 1,3 , and 7 , and washed $2 \times 5 \mathrm{~min}$ with $500 \mu \mathrm{l}$ of PBS followed by a 20 -min incubation $\left(37^{\circ} \mathrm{C}\right.$ at $\left.5 \% \mathrm{CO}_{2}\right)$ with $500 \mu \mathrm{L}$ of PBS containing calcein AM $(2 \mu \mathrm{M})$ and ethidium homodimer-1 $(4 \mu \mathrm{M})$. After staining, hydrogels were again washed $(2 \times 5 \mathrm{~min}$ with $500 \mu \mathrm{l}$ of PBS) before imaging. Hydrogels were transferred to a chamber slide (Nunc Lab-Tek ${ }^{\mathrm{TM}}$ II Chamber Slide, Glass, 1 well) and imaged with confocal microscopy (Zeiss LSM $\times 800, \times 10$ objective at a zoom of $\times 0.6$ and frame size of $1,024 \times 1,024$ for each image, $200 \mu \mathrm{m} \mathrm{z}$-stack, three images per hydrogel sample). Orthogonal projections were made of each z-stack, and live (green) and dead (red) cells were counted using ImageJ.

\section{Flow Cytometry for THP-1 Cell Differentiation}

To confirm differentiation of THP-1 cells into macrophages within 3D culture, hydrogels with encapsulated THP-1 cells treated with PMA (for differentiation into macrophages) or untreated THP-1 monocytes were washed twice in $2 \mathrm{ml}$ in 1xPBS for $5 \mathrm{~min}$ each. Hydrogels were put into $1.5 \mathrm{ml}$ Eppendorf tubes (4 hydrogels per tube), and a $1 \mathrm{ml}$ solution of collagenase $(300 \mathrm{U} / \mathrm{ml})$ (Sigma Aldrich) was added to degrade the hydrogel. Tubes were placed in a $\mathrm{CO}_{2}$ incubator at $37^{\circ} \mathrm{C}$. The solution was triturated every $10 \mathrm{~min}$ for up to $30 \mathrm{~min}$ until the solution could be pipetted freely. The now-digested hydrogel solution was centrifuged $(150 \mathrm{~g}, 5 \mathrm{~min})$ to pellet the cells. Monocytes (THP-1 cells) or macrophages (differentiated THP1 cells) from $2 \mathrm{D}$ culture $\left(1 \times 10^{6}\right.$ cells $)$ were removed from plates and similarly centrifuged in $1.5 \mathrm{ml}$ Eppendorf tubes. Pelleted cell samples were washed with $2 \%$ bovine serum albumin (BSA) in PBS and resuspended in $100 \mu \mathrm{l}$ of $2 \%$ BSA in PBS, and $5 \mu \mathrm{l}$ of CD11 b antibody was added. Samples were placed on ice in the dark for $30 \mathrm{~min}$ and then centrifuged followed by washing with $2 \%$ BSA in PBS. Cells were then fixed in $4 \%$ paraformaldehyde in $1 \mathrm{xPBS}$ for $15 \mathrm{~min}$ at room temperature, centrifuged, and washed $2 \times 100 \mu \mathrm{l}$ in Intracellular Staining Permeabilization Wash Buffer (BioLegend). Cells were resuspended in $100 \mu \mathrm{l}$ of Intracellular Staining Permeabilization Wash Buffer, and $5 \mu$ of CD68 was added to each sample followed by incubation on ice for $30 \mathrm{~min}$. Cells were washed $1 \times 100 \mu$ of Intracellular Staining Permeabilization Wash Buffer. Flow cytometry was performed on ACEA Novocyte Flow Cytometer. Samples were briefly vortexed before each run. 100,000 cell counts were collected for each sample and were analyzed in triplicate, and fluorescence intensities (height) were generated and overlaid.

\section{DBCO Fluorophore Staining for Fixed Samples}

THP-1 cells as monocytes, THP-1 cells differentiated into macrophages using PMA, and HEK293T cells were seeded onto pre-treated coverslips. Cells were fixed with 4\% PFA for $10 \mathrm{~min}$ at room temperature, and then washed $3 \times 5 \mathrm{~min}$ with $1 \mathrm{x}$ PBS. Cells were then incubated with $30 \mu \mathrm{M}$ DBCO-488 or an equivalent volume of water as a control for $40 \mathrm{~min}$ at $37^{\circ} \mathrm{C}$. Cells were washed $3 \times 5 \mathrm{~min}$ with $1 \mathrm{xPBS}$ at room temperature on a rocker. Coverslips were mounted with mounting media with DAPI and imaged using confocal microscopy.

\section{DBCO Fluorophore Staining for Live Samples}

THP-1 cells as monocytes, THP-1 cells differentiated into macrophages using PMA, HEK cells, and CCL151 fibroblast cells were seeded onto pre-treated coverslips. Cells were then incubated with $30 \mu \mathrm{M}$ DBCO-488 or an equivalent volume of water as a control for $40 \mathrm{~min}$ at $37^{\circ} \mathrm{C}$. Cells were washed. Cells were fixed with $4 \%$ PFA for $10 \mathrm{~min}$ at room temperature, and then washed $3 \times 5$ min with $1 x$ PBS. Coverslips were mounted with mounting media with DAPI and imaged using confocal microscopy.

\section{Invasion Assay in 2D Culture for Imaging With CuAAC Bacteria}

UV sterilized cover glasses (Fisher Scientific, catalogue number 12-545-80) were coated with $500 \mu \mathrm{l}$ of $0.1 \mathrm{mg} / \mathrm{ml}$ poly-Lornithine (Sigma-Aldrich) in 24-well plate overnight. The poly-L-ornithine was removed, and the cover glasses were washed with PBS twice. THP-1 cells were seeded on the cover glasses in 24-well plates with RPMI media $\left(1 \times 10^{5}\right.$ cells/well). THP-1 cells were differentiated into macrophages through stimulation with PMA for 3 days. Cells were then washed with RPMI media without antibiotics twice. For invasion, E. coli $\triangle M u r Q-K U$ was grown and remodeled following the protocols above for CuAAC. $20 \mu \mathrm{l}$ of bacterial suspension $\left(\mathrm{OD}_{600 \mathrm{~nm}}=2.0\right)$ was added to each well, and the samples were incubated at $37^{\circ} \mathrm{C}$ and $5 \% \mathrm{CO}_{2}$ for $30 \mathrm{~min}$. After incubation, the media was removed, and fresh media with gentamycin $(1: 1,000)$ was added to kill extracellular bacteria, incubating for $30 \mathrm{~min}$ at $37^{\circ} \mathrm{C}$ and $5 \% \mathrm{CO}_{2}$. The media then was removed, and the cells were rinsed twice with $1 \mathrm{xPBS}$ at room temperature. Cells were fixed $4 \%$ paraformaldehyde in $1 \times$ PBS for $10 \mathrm{~min}$ at room temperature and rinsed twice with 1xPBS. Then, cells were permeabilized with $1 \%$ Triton-X in PBS for $10 \mathrm{~min}$ at room temperature and washed $3 \times 5$ min with $1 \times$ PBS with $0.2 \%$ Tween20 and $1.5 \%$ BSA at room temperature on a rocker. PBS $(500 \mu \mathrm{l})$ with $0.2 \%$ Tween- 20 and $0.1 \%$ Triton-X was added to each well to prepare for the click reaction. To each well was sequentially added $1 \mathrm{mM} \mathrm{CuSO}_{4}$ solution, $140 \mu \mathrm{M}$ BTTAA, $1.2 \mathrm{mM}$ freshly prepared (+)-sodium (L) ascorbate (SigmaAldrich), and $20 \mu \mathrm{M}$ of Alk488. The click reaction was performed at room temperature for $30 \mathrm{~min}$ while shaking. The cells were washed $3 \times 5$ min with $1 \times$ PBS with $0.2 \%$ Tween- 20 and $1.5 \%$ BSA at room temperature on a rocker. The cells were then stained with 1:200 Phalloidin-TRITC (F-actin stain) in 1.5\% BSA in $1 \mathrm{xPBS}$ for $1 \mathrm{~h}$ at room temperature. The cells were washed $3 \times$ 5 min with $1 \times$ PBS with $0.2 \%$ Tween and $1.5 \%$ BSA at room temperature on a rocker and then were mounted on glass slides with 4,6-diamidino-2-phenylindole (Invitrogen) for super resolution imaging. 


\section{Invasion Assay in 2D Culture for Imaging With SPAAC Bacteria}

Sterile cover glasses (Fisher Scientific, catalogue number 12-54580) were coated with $500 \mu \mathrm{l} \mathrm{of} 0.1 \mathrm{mg} / \mathrm{ml}$ poly-L-ornithine (Sigma-Aldrich) in 24-well plate overnight. The poly-Lornithine was removed, and the cover glasses were washed with PBS twice. THP-1 cells were seeded on the cover glasses in 24 -well plates with RPMI media $\left(1 \times 10^{5}\right.$ cells/well $)$. THP- 1 cells were differentiated into macrophages through stimulation with PMA for 3 days. Cells were then washed with RPMI media without antibiotics twice. For invasion, E. coli $\triangle M u r Q-K U$ was grown and remodeled following the protocols above for SPAAC. Following remodeling and labeling with DBCO-488, $20 \mu \mathrm{l}$ of bacteria $\left(\mathrm{OD}_{600 \mathrm{~nm}}=2.0\right)$ was added to each well, and the samples were incubated at $37^{\circ} \mathrm{C}$ and $5 \% \mathrm{CO}_{2}$ for $30 \mathrm{~min}$. After incubation, the media was removed, and fresh media with gentamycin $(1: 1,000)$ was added to kill extracellular bacteria, incubated for $30 \mathrm{~min}$ at $37^{\circ} \mathrm{C}$ and $5 \% \mathrm{CO}_{2}$. The media then was removed, and the cells were rinsed twice with $1 \times \mathrm{PBS}$ at room temperature. Cells were fixed $4 \%$ paraformaldehyde in 1xPBS for $10 \mathrm{~min}$ at room temperature and rinsed twice with $1 \mathrm{xPBS}$. Then, cells were permeabilized with $1 \%$ Triton-X in PBS for $10 \mathrm{~min}$ at room temperature and washed $3 \times 5$ min with $1 \mathrm{xPBS}$ with $0.2 \%$ Tween-20 and $1.5 \%$ BSA at room temperature on a rocker. The cells were then stained with 1:200 Phalloidin-TRITC (F-actin stain) in $1.5 \% \mathrm{BSA}$ in $1 \mathrm{xPBS}$ for $1 \mathrm{~h}$ at room temperature. The cells were washed $3 \times 5$ min with $1 \times$ PBS with $0.2 \%$ Tween and $1.5 \% \mathrm{BSA}$ at room temperature on a rocker and then were mounted on glass slides with 4,6-diamidino-2-phenylindole (Invitrogen) for confocal microscopy imaging.

\section{Invasion Assay in 3D Culture for Imaging With CuAAC Bacteria}

THP-1 cells were encapsulated with an adapted version of the protocol described above. Here, cells suspended in hydrogel precursor solution were prepared as before, and then $20 \mu \mathrm{l}$ of hydrogel precursor solution was pipetted onto a $1 \mathrm{ml}$ syringe mold (instead of a gasket mold) resulting in 100,000 cells per hydrogel. Hydrogels were formed by photopolymerization and placed into 24-well plates for 3D cell culture and differentiation with PMA for 3 days as before. Samples were then washed with RPMI media without antibiotics twice. For invasion, $20 \mu \mathrm{l}$ of E. coli $\triangle M u r Q-K U\left(\mathrm{OD}_{600 \mathrm{~nm}}=2.0\right)$, grown and remodeled as noted above for the CuAAC protocol, was added to each well for $60 \mathrm{~min}$, and the samples were incubated at $37^{\circ} \mathrm{C}$ and $5 \% \mathrm{CO}_{2}$. After incubation, the media was removed, and fresh media with gentamycin $(1: 1,000)$ was added to kill extracellular bacteria for $60 \mathrm{~min}$ at $37^{\circ} \mathrm{C}$ and $5 \% \mathrm{CO}_{2}$. After $60 \mathrm{~min}$, the media was removed, and the cells were rinsed twice with $1 \times$ PBS at room temperature. Cells were fixed $4 \%$ paraformaldehyde in $1 \mathrm{xPBS}$ for $15 \mathrm{~min}$ at room temperature. Fixed cells were rinsed $3 \times 5$ min with $1 \times$ PBS, and were permeabilized with $1 \%$ Triton-X in PBS for $30 \mathrm{~min}$ at room temperature. Cells were washed $3 \times$ 5 min with $1 x$ PBS with $0.2 \%$ Tween-20 and $1.5 \%$ BSA at room temperature on a rocker. PBS $(500 \mu \mathrm{l})$ with $0.2 \%$ Tween-20 and
$0.1 \%$ Triton-X was added to each well to prepare for the click reaction. To each well was sequentially added $1 \mathrm{mM} \mathrm{CuSO}$ solution, $128 \mu \mathrm{M}$ Tris [(1-benzyl-1H-1,2,3-triazol-4-yl)methyl] amine, $1.2 \mathrm{mM}$ freshly prepared (+)-sodium (L) ascorbate (Sigma-Aldrich), and $20 \mu \mathrm{M}$ of Alk488. The click reaction was performed at room temperature for $1 \mathrm{~h}$ while shaking. The cells were washed $2 \times 30 \mathrm{~min}$ with $1 \times \mathrm{xBS}$ with $0.2 \%$ Tween- 20 and $1.5 \% \mathrm{BSA}$ at room temperature on a rocker. The cells were washed overnight in $1 \times$ PBS with $0.2 \%$ Tween- 20 and $1.5 \%$ BSA at $4^{\circ} \mathrm{C}$. The next day, the cells were washed $2 \times 30 \mathrm{~min}$ with $1 \mathrm{xPBS}$ with $0.2 \%$ tween-20 and $1.5 \%$ BSA at room temperature on a rocker. Cells were stained with 4,6diamidino-2-phenylindole (DAPI) for $30 \mathrm{~min}$ and were washed $3 \times 10 \mathrm{~min}$ with $0.2 \%$ Tween- 20 and $1.5 \%$ BSA at room temperature on a rocker. Hydrogels were moved to glass chamber well slides for confocal imaging.

\section{Invasion Assay in 3D Culture for Imaging With SPAAC Bacteria}

THP-1 cells were encapsulated as described above. Hydrogels were formed by photopolymerization and placed into 24-well plates for 3D cell culture and differentiation with PMA for 3 days as before. Samples were then washed with RPMI media without antibiotics twice. For invasion, $20 \mu \mathrm{l}$ of $E$. coli $\triangle M u r Q-K U\left(\mathrm{OD}_{600 \mathrm{~nm}}=2.0\right)$, grown and remodeled as noted above with the SPAAC protocol, was added to each well for $60 \mathrm{~min}$, and the samples were incubated at $37^{\circ} \mathrm{C}$ and $5 \% \mathrm{CO}_{2}$. After incubation, the media was removed, and fresh media with gentamycin $(1: 1,000)$ was added to kill extracellular bacteria for $60 \mathrm{~min}$ at $37^{\circ} \mathrm{C}$ and $5 \% \mathrm{CO}_{2}$. After $60 \mathrm{~min}$, the media was removed, and the cells were rinsed twice with $1 \mathrm{xPBS}$ at room temperature. Cells were fixed $4 \%$ paraformaldehyde in $1 \mathrm{xPBS}$ for $15 \mathrm{~min}$ at room temperature. Fixed cells were rinsed $3 \times 5 \mathrm{~min}$ with $1 \times \mathrm{PBS}$, and were permeabilized with $1 \%$ Triton-X in PBS for $30 \mathrm{~min}$ at room temperature. Cells were washed $3 \times 5$ min with $1 \times$ PBS with $0.2 \%$ tween-20 and $1.5 \%$ BSA at room temperature on a rocker Cells were stained with DAPI for $30 \mathrm{~min}$ and were washed $3 \times$ $10 \mathrm{~min}$ with $0.2 \%$ Tween-20 and $1.5 \%$ BSA at room temperature on a rocker. Hydrogels were moved to glass chamber well slides for confocal imaging.

\section{Live Cell Imaging}

THP-1 cells were seeded into 8-well chamber slides and treated with $20 \mathrm{nM}$ PMA to differentiate for 3 days. Media was replaced to RPMI without antibiotics. Cells were then incubated with Cell Mask Orange for $15 \mathrm{~min}$. The media was changed and SPAAC labeled bacteria (see Bacterial Labeling and Remodeling) with strain promoted azide-alkyne cycloaddition (SPAAC) was added to the appropriate wells. The cells were imaged using the Andor Dragonfly 505 spinning disk confocal microscope with a PlanApochromat $63 \mathrm{x} / 1.47$ oil objective to visualize the engulfment of bacteria cells in real time. Excitation of labeled bacteria and Cell Mask Orange was achieved with a $637 \mathrm{~nm}$ laser at $2 \%$ power and a $561 \mathrm{~nm}$ laser at $0.2 \%$ power. $3 \mathrm{D}$ volumes were acquired every $1 \mathrm{~min}$ for $2 \mathrm{~min}$. 


\section{Confocal Microscopy for 2D Samples}

$P$. aeruginosa images and $2 \mathrm{D}$ invasion images were taken on a Zeiss LSM 800 microscope with Plan-Apochromat 63x/1.4 Oil differential interference contrast (DIC) M27 objective. Excitation of DBCO-488 was achieved with $488 \mathrm{~nm}, 2 \%$ laser excitations. Excitation of phalloidin-TRITC was achieved with $562 \mathrm{~nm}, 0.2 \%$ laser excitations. Excitation of DAPI was achieved with $405 \mathrm{~nm}$, $1 \%$ laser excitation. Scan mode was frame and bidirectional. Program Carl Zeiss ZEN 2012 was used to process the raw data to construct the images. Processing and filtering settings were kept constant and image intensity was preserved with the raw image scale option in Zen 2012. Two-dimensional (2D) images were generated. Scale bars were made with the line measurement tool function.

\section{Structured Illumination Microscopy (SIM) for 2D Samples}

Bacterial labeling of EQKU cells was imaged on a Zeiss Elyra PS.1 microscope with Plan-Apochromat $63 \mathrm{x} / 1.4$ oil differential interference contrast (DIC) M27 objective. Excitation of Alk488 was achieved with $488 \mathrm{~nm}$ laser excitation, and the camera exposure time was set to $100.0 \mathrm{~ms}$. The raw data contained five rotations with $0.110 \mu \mathrm{m}$ z-stack interval. Images were processed in Carl Zeiss ZEN 2012 to construct SIM images. Processing and filtering settings were kept constant and image intensity was preserved using the raw image scale option. Twodimensional (2D) SIM images and 2D maximum intensity projection images were generated.

\section{Confocal Microscopy Imaging for 3D Samples}

3D culture samples were imaged with confocal microscopy. Images were taken on Zeiss LSM800 with Plan-Apochromat $63 \mathrm{X} / 1.40$ Oil DIC M27 objective and frame size of $1,024 \times$ 1,024 pixels. Z-stacks were $200 \mu \mathrm{m}$ with $0.2 \mu \mathrm{m}$ slices. Excitation of 4,6-diamidino-2-phenylindole and Alk488 was achieved with 405 and $488 \mathrm{~nm}$ lasers, respectively. Pixel, line, and frame time were $1.03 \mu \mathrm{s}, 4.95 \mathrm{~ms}$, and $5.06 \mathrm{~s}$, respectively. Scan direction was bidirectional, and an average of four scans per image was utilized. ZEN 2012 (Zeiss) was used to process the images and prepare $\mathrm{Z}$-stack projections.

\section{ELISA Preparation}

Three days before stimulation with bacteria, macrophage samples were seeded and encapsulated for $2 \mathrm{D}$ and $3 \mathrm{D}$ culture, respectively. For $2 \mathrm{D}$ culture, cells were seeded at $1 \times 10^{6}$ cells per well in a 6 well plate. For $3 \mathrm{D}$ culture, hydrogels were formed in gasket molds as described above, and four hydrogels $(250,000$ cells per hydrogel) were placed per well in a 6 well plate (total of $1 \times 10^{6}$ cells per well). All cells were differentiated for 3 days with $200 \mathrm{nM}$ PMA. The cells were washed twice with RPMI media without antibiotics. Cells were provided RPMI media without antibiotics after the washes. The day of the stimulation with bacteria, bacterial overnights were diluted to $\mathrm{OD}=2.0$, and $20 \mu \mathrm{l}$; of these bacteria was added to each well. To the control samples,
$20 \mu \mathrm{l}$ of sterile water was added. Plates were incubated for $4 \mathrm{~h}$ in an incubator $\left(37^{\circ} \mathrm{C}, 5 \% \mathrm{CO}_{2}\right)$. After $4 \mathrm{~h}$, the supernatant was removed, and it was stored at $-20^{\circ} \mathrm{C}$ until shipment $(1 \mathrm{ml}$ total volume per sample) to University of Maryland Cytokine Core for analysis by ELISA.

\section{RESULTS AND DISCUSSION}

\section{Bacterial Remodeling and Labeling Utilizing CuAAC and SPAAC}

A previously engineered strain of E. coli, E. coli $\triangle M u r Q K U$ (EQKU) that expresses recycling enzymes AmgK and MurU was used to specifically label the NAM residue of PG (Liang et al., 2017). Through remodeling with the 2 -azido $N$-acetyl muramic acid sugar (AzNAM), we observed fluorescent labeling specifically to the cell wall of the EQKU PG following the copper catalyzed azide-alkyne cycloaddition (CuAAC) click reaction to install an alkyne fluorophore (Alk488) which matches previously reported data from our lab (Figure 2).

As the Pseudomonas family naturally express AmgK and MurU, we sought to expand our CuAAC labeling methodology beyond EQKU into the pathogenic species Pseudomonas aeruginosa, an opportunistic, pathogenic species of bacteria that is known to break through mucosal barriers particularly in hospital infections and is extremely antibiotic resistant (Lister et al., 2009). Previous work has shown success in applying this CuAAC methodology to P. putida, B. subtilis, and H. pylori (Liang et al., 2017; Taylor et al., 2020; Taylor et al., 2021). Once again utilizing the AzNAM probe and a lethal dose of the cell wall targeting antibiotic, fosfomycin, the first steps of PG biosynthesis are inhibited and we observed incorporation of the AzANM probe using AmgK and MurU recycling enzymes into the $P$. aeruginosa cell wall as confirmed by fluorescent microscopy following CuAAC click reaction (Figure 2).

Although the CuAAC click reaction allows for the visualization of the cell wall, reaction requires the cells to be fixed due to the toxic nature of copper to cells, eliminating the ability of tracking the bacteria in real time to get engulfed by macrophages. Therefore, we explored another bioorthogonal reaction called the strain promoted azide-alkyne cycloaddition (SPAAC) that does not require a cytotoxic catalyst, allowing for the possibility of live cell imaging (Baskin et al., 2007). Some applications of SPAAC include labeling proteins, lipids, glycans on mammalian cells (Neef and Schultz, 2009; Nikić et al., 2015; Debets et al., 2020), in living animals such as mice (Chang et al., 2010), ribonucleic acid (RNA) (Wang et al., 2020), and more recently, on bacteria using penicillin binding proteins (Brown et al., 2021b). Since we previously remodeled both $E$. coli and $P$. aeruginosa with AzNAM, we utilized a dibenzocyclooctyne (DBCO) 488 dye as our strained alkyne. Through a detailed study of DBCO concentrations and click reaction times, we determined that $40 \mathrm{~min}$ at $37^{\circ} \mathrm{C}$ with $30 \mu \mathrm{M}$ DBCO-488 was sufficient to label the cell wall in E. coli for microscopy (Figure 2, Supplementary Figure S1), demonstrating that the DBCO dye can cross the outer membrane of the bacterial cell. Flow cytometry revealed that a concentration higher than $30 \mu \mathrm{M}$ DBCO leads to a secondary population of unlabeled cells in E. coli. Interestingly, the SPAAC reaction on AzNAM remodeled $P$. 


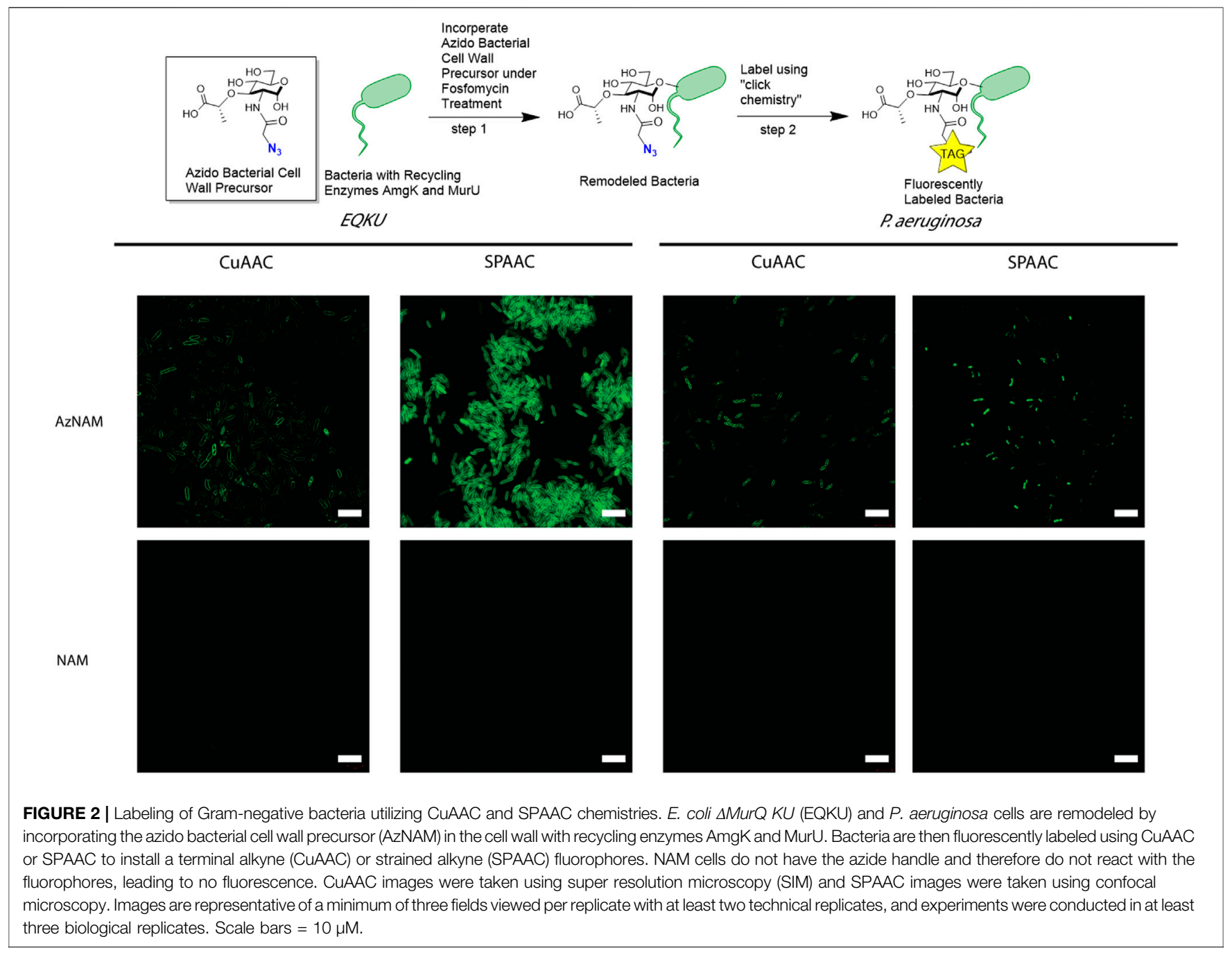

aeruginosa appeared to be located predominantly in the poles and leads to a shorter cell length than CuAAC labeled $P$. aeruginosa (Figure 2). A plate reader growth curve assay was utilized to observe how growth rates of species were different following the click reaction on the living cells and found that both cell type's growth rates were unaffected by the chemistry occurring on the cell wall (Supplementary Figure S2, Figure 3). We hypothesize that differences in cell wall architecture between the two species lead to the modification being more permittable in E. coli and is causing the probe to get stuck in the poles of the P. aeruginosa cells. With the $\mathrm{CuAAC}$ and SPAAC reactions working well in E. coli, we proceeded with this specific species to visualize engulfment by macrophages in both $2 \mathrm{D}$ and $3 \mathrm{D}$ invasion models.

\section{Development of 3D Synthetic Matrix for Macrophage Culture}

To fabricate a $3 \mathrm{D}$ synthetic matrix with tunable properties in the range of those of the healthy gut, we utilized an 8-arm PEG functionalized with norbornene end groups (PEG-8-Nb) linked with a matrix metalloproteinase (MMP) - degradable sequence (GCRDVPMS $\downarrow$ MRGGDRCG) (Ovadia et al., 2018) that is responsive to MMP-2 amongst other enzymes secreted by monocytes and macrophages (Ahmad et al., 2019; Chellat et al., 2005). Additionally, these hydrogels were modified with the integrin binding peptide CGKGYIGSR, derived from the laminin $\beta_{1}$ chain, to promote cell adhesion inspired by the laminin-rich ECM of the basement membrane of the gut (Smithmyer et al., 2014; Yamada et al., 2011; Rezakhani et al., 2021). The hydrogels were formed rapidly through light-triggered thiol-ene click chemistry via a step growth mechanism, as the norbornene groups on the PEG are coupled to the thiols presented by the cysteines in the difunctional MMPdegradable linker peptide and monofunctional integrin binding peptide (Figures 3A,B) (Fairbanks et al., 2009). The reaction was initiated using the photoinitiator lithium phenyl-2,4,6trimethylbenzoylphosphinate (LAP) and low, cytocompatible doses of light $\left(10 \mathrm{~mW} / \mathrm{cm}^{2}\right.$ at $365 \mathrm{~nm}$ for $\left.2 \mathrm{~min}\right)$. These 


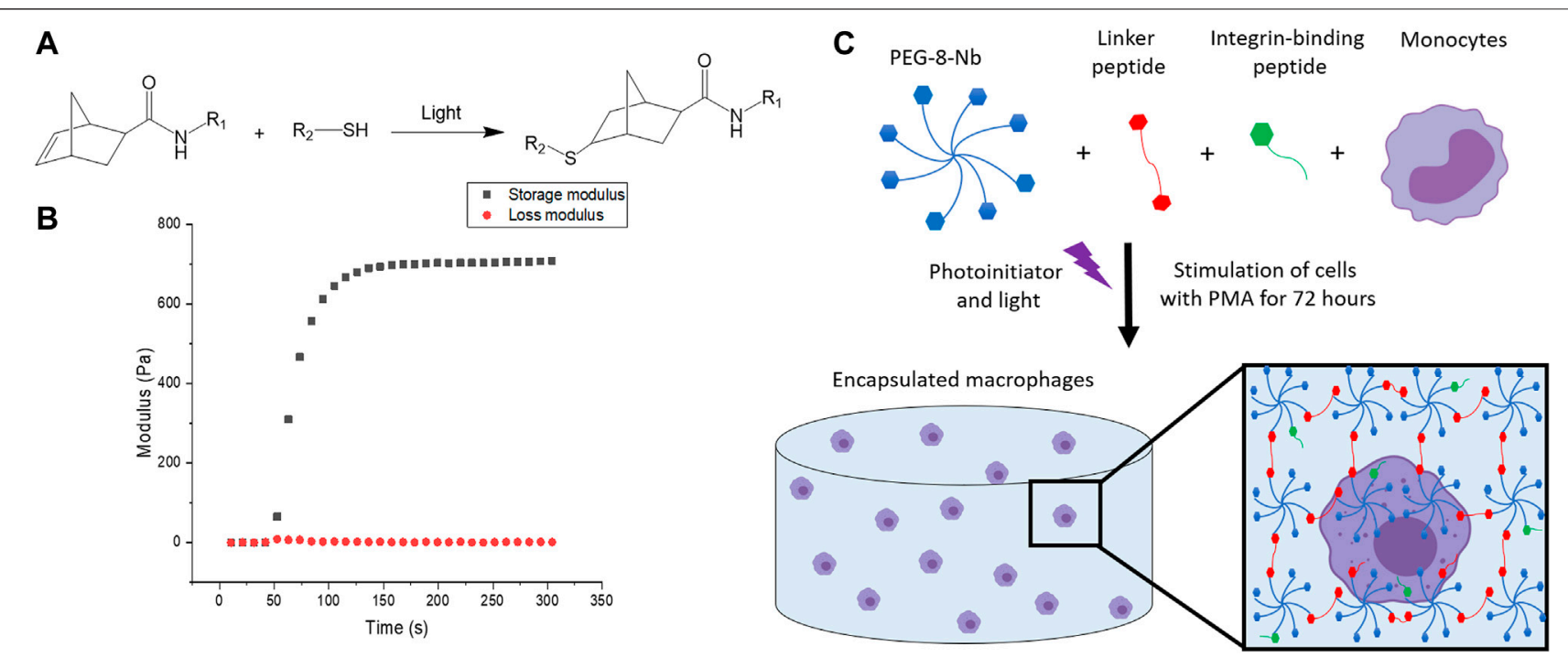

FIGURE 3 | Overview of hydrogel design. (A) Hydrogels were formed using thiol-ene click chemistry with norbornenes on the PEG and thiols on the difunctional linker and monofunctional integrin binding peptides. (B) Hydrogels are rapidly formed upon the application of light. The increase in storage modulus, monitored with in situ rheometry, indicates crosslinking events, and complete hydrogel formation was observed within 2 min. This final modulus, converted to Young's modulus by rubber elasticity theory for ease of comparison to native tissues, is relevant for mimicking the modulus or "stiffness" of the healthy gut. (C) The hydrogel network is composed of 8-arm PEG-norbornene (blue), thiol-containing linker peptide (red), and thiol-containing integrin binding peptide (green). Components were photopolymerized with a low, cytocompatible dose of light $\left(10 \mathrm{~mW} / \mathrm{cm}^{2}\right.$ at $365 \mathrm{~nm}$ for $2 \mathrm{~min}$ ) to form a hydrogel, and the monocyte cells in the hydrogel subsequently were differentiated into macrophages through stimulation with PMA for $72 \mathrm{~h}$. Schematic not to scale.

synthetic bioinspired hydrogels were designed with a Young's modulus $(\mathrm{E} \sim 2.6 \pm 0.8 \mathrm{kPa}$ ) to mimic the "stiffness" of the healthy gut (Johnson et al., 2013), as confirmed by shear rheometry (Figure 3C).

This type of PEG-peptide hydrogel, formed by a photoinitiated thiol-ene step growth polymerization under similar conditions $\left(10 \mathrm{~mW} / \mathrm{cm}^{2}\right.$ at $365 \mathrm{~nm}$ for $\left.<10 \mathrm{~min}\right)$, has been used previously to culture a wide variety of cell types, including human mesenchymal stem cells, induced pluripotent stem cells, and breast cancer cells (Tibbitt and Anseth, 2009; Caliari and Burdick, 2016; Ovadia et al., 2018; Gerecht et al., 2007; Benoit et al., 2008). However, as the mechanism of hydrogel polymerization involves free-radicals, the viability of sensitive cell types can be impacted during cell encapsulation and hydrogel formation (Caliari and Burdick, 2016; Ovadia et al., 2018; Macdougall et al., 2018). Accordingly, we examined cell viability upon encapsulation and during $3 \mathrm{D}$ cell culture within these materials. Here, THP-1 cells were selected as a human monocytic cell line that are commonly differentiated into macrophage cells, as human primary tissue macrophages cannot be readily expanded ex vivo (Daigneault et al., 2010). We first differentiated monocytes into macrophages on TCPS and subsequently encapsulated these cells. We observed low viability in the hydrogels (Supplementary Figure S4). Therefore, we examined encapsulating monocytes and then differentiating them into macrophages within the matrix, which also mimics aspects of the natural process of monocyte arrival and differentiation into macrophages within the native gut. Importantly, monocytes were successfully encapsulated within the hydrogels and exhibited high viability throughout
3D culture (Figure 4A, Supplementary Figure S5). Based on observations from prior studies with other human cell types, we speculate that the cytotoxic effects of hydrogel formation on macrophages were related to their sensitivity to free radical exposure (Caliari and Burdick, 2016; Macdougall et al., 2018; Ovadia et al., 2018); opportunities for future investigations include examination of the specific cause(s) of macrophage death in this system and related approaches for rescuing human macrophage cell viability (e.g., inclusion of different ligands for promoting cell health (Ovadia et al., 2018), examination of different photoinitiators or irradiation wavelengths (Bryant et al., 2000; Williams et al., 2005; Zeng et al., 2021), or use of a different hydrogel formation mechanism (Macdougall et al., 2018). For the purpose of our studies here, focused on probing bacterial cell-macrophage interactions, the system established functioned well for maintaining monocyte viability and allowing their differentiation into macrophages during 3D culture, which has broad utility for probing not only macrophage-bacteria interactions but also monocytebacteria interactions in future studies.

After confirmation of successful culture of THP-1 monocyte cells, monocytes were differentiated into macrophage cells through stimulation with phorbol 12-myristate 13-acetate (PMA) over 3 days based on literature precedent in two dimensions (Zhang et al., 2008; Daigneault et al., 2010; Lund et al., 2016). To probe differentiation, the hydrogels were digested using collagenase and centrifuged to isolate the cells from the materials to study changes in their extracellular and intracellular macrophage markers. Through subsequent staining and flow cytometry, differentiation was confirmed for the recovered 

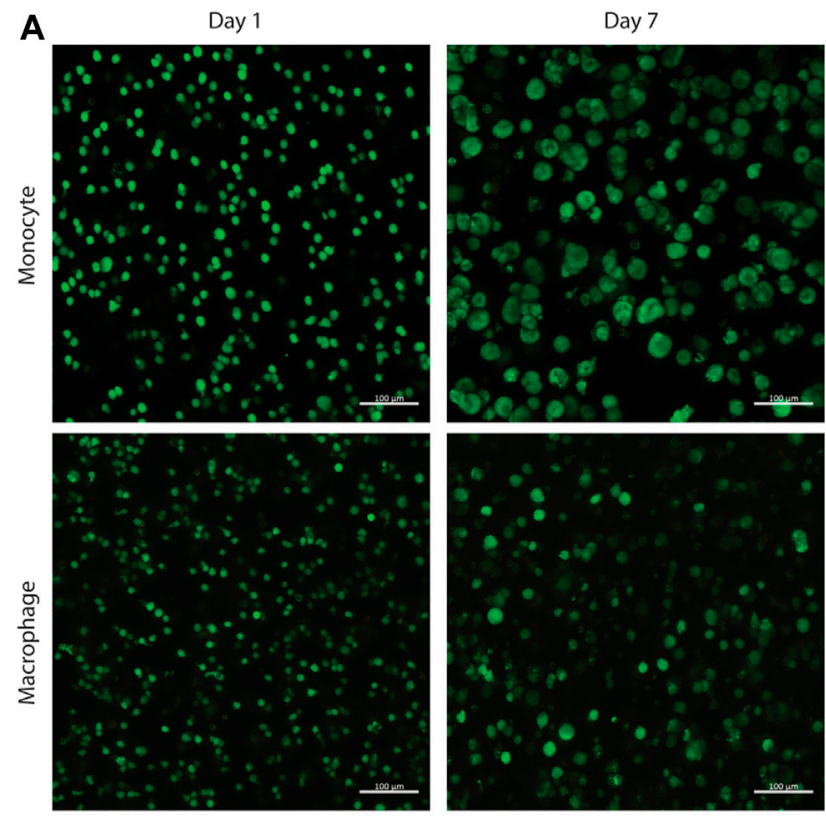

B

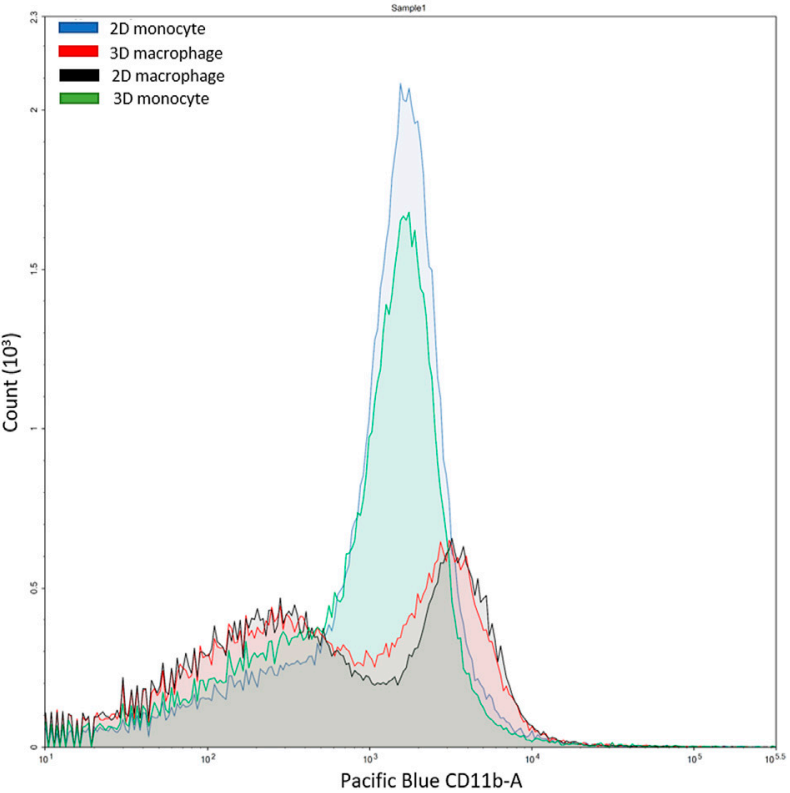

FIGURE 4 | Confirmation of cell viability and cell differentiation in 3D culture. (A) Live/dead cytotoxicity results of THP-1 cells (monocytes) and THP-1 cells differentiated with PMA (macrophages) in PEG-peptide hydrogels. Confocal images are representative of a minimum of three fields per view per hydrogel of three biological replicates. (B) Flow cytometry data of macrophages and monocytes in 2D or 3D culture stained for extracellular macrophage marker CD11 b. 2D (blue) and 3D monocyte (green) profiles match each other, and 2D (red) and 3D (black) macrophage profiles match each other, showing differentiation is achieved in the 3D hydrogel. Plot is representative of three biological replicates and two technical replicates.

cells using macrophage extracellular and intracellular markers, CD11 b and CD68, respectively (Figure 4B, Supplementary Figure S6). This hydrogel digestion method can be applied to isolate a wide variety of $3 \mathrm{D}$ cultured mammalian cells for downstream flow cytometry analysis. Further, these macrophages also exhibited high viability in the hydrogels (Figure 4A, Supplementary Figure S5).

\section{Invasion of Fluorescent Bacteria Into Macrophages in 2D and 3D Culture}

With the ability to fluorescently label $E$. coli with CuAAC and SPAAC, macrophages were invaded with bacteria on $2 \mathrm{D}$ culture on TCPS and into 3D cultures within synthetic hydrogels. For the CuAAC click reactions, EQKU were remodeled with AzNAM and subsequently invaded into macrophages, followed by fixation and the CuAAC reaction. After invasion for $1 \mathrm{~h}$, we observed engulfment of the bacteria by the macrophages in both $2 \mathrm{D}$ and $3 \mathrm{D}$ culture (Figure 5), indicating that this system will have utility in identifying naturally released bacterial peptidoglycan fragments. We also noted that the bacteria in $3 \mathrm{D}$ culture invasion assay appeared to be more similar in size to the expected biologicallyrelevant lengths of 1-2 $\mu \mathrm{m}$, whereas bacteria were larger in $2 \mathrm{D}$ invasion (Ei-Hajj and Newman, 2015). Overall, these observations suggest that the dimensionality of the culture system affects rate of bacterial breakdown to smaller fragments and bacterial growth independently of macrophages in these types of $3 \mathrm{D}$ materials. We also remodeled E. coli and labeled with SPAAC prior to invasion into macrophages. Following fixation and staining, we can observe EQKU within the macrophages in $2 \mathrm{D}$ and 3D culture (Figure 5). This pre-labeling method of the bacteria with SPAAC is also advantageous as it allows us to visualize the engulfment in real time. Within 5 minutes in live samples, we can observe engulfment of EQKU by macrophages in 2D culture (Figure 5, Supplementary Videos S1, S2).

Next, we wanted to determine if remodeled EQKU can be invaded into macrophages and a subsequent SPAAC click chemistry can be performed once the bacteria are already inside of the cell; this would mimic the CuAAC labeling method. Following the engulfment of the bacterial cells, the macrophage cells were fixed and then treated the cells with DBCO-488 to label the bacteria in the system. The confocal microscopy images revealed the labeled of EQKU cells but also significant, non-specific binding of the fluorophore to the cells (Supplementary Figure S7) despite rigorous washing steps. To determine the cause of the background dye labeling, macrophage cells were treated as well as monocytes (undifferentiated THP-1 cells) and HEK293T cells with $30 \mu \mathrm{M}$ DBCO-488 after fixing the cells. We determined that the utilization of a fixative agent causes the DBCO dye to nonspecifically bind to the macrophage cells as well as THP-1 monocyte cells and HEK293T cells; this behavior has been observed in the literature (Supplementary Figure S8) (Loebel et al., 2019). Interestingly, when treating live cells with the DBCO dye prior to fixation, only the macrophage cells continue to have nonspecific binding while THP1 monocyte cells, HEK293T, and CCL151 fibroblast cells do not nonspecifically 


\section{A}

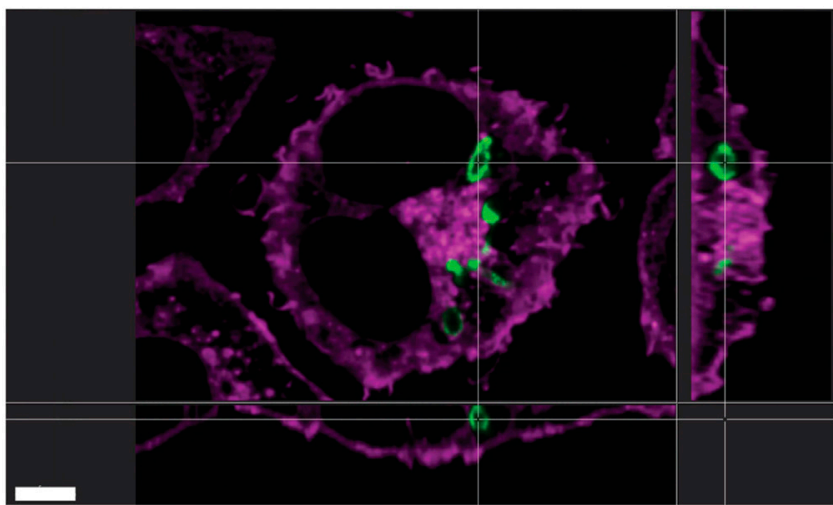

B

2D

\section{CUAAC}

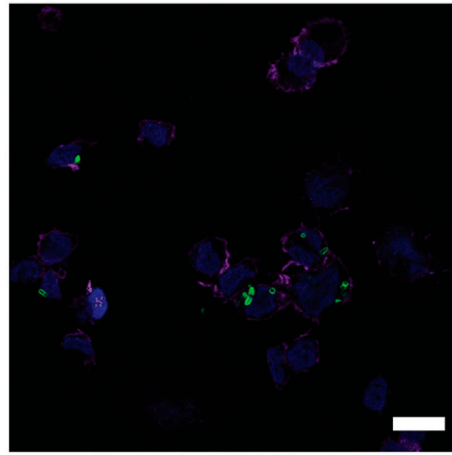

C

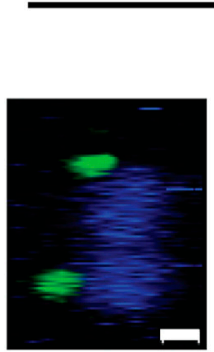

\section{CUAAC}

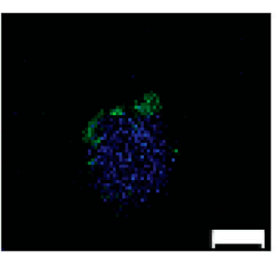

SPAAC

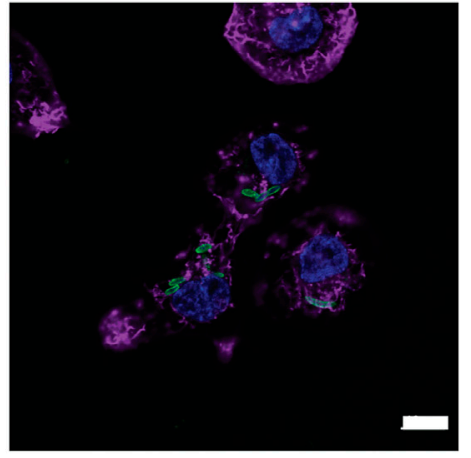

3D

SPAAC

FIGURE 5 |THP-1 macrophage cells invaded by remodeled E. coli $\triangle M$ MUR KU in 2D and 3D culture. E. coli $\triangle M$ MUR KU (EQKU) cells are remodeled by incorporating the azido bacterial cell wall precursor in the cell wall with recycling enzymes AmgK and MurU. (A) EQKU cells labeled with DBCO-488 using SPAAC were invaded into macrophage cells and observed with Andor Dragonfly microscope. Bacteria (green) can be visualized within macrophages (purple) as shown by ortho view above. Scale bar $=5 \mu \mathrm{m}(\mathbf{B}, \mathbf{C})$ The CuAAC condition bacteria were invaded into THP-1 macrophage cells and fixed prior to the CuAAC click labeling (bacteria, green) and subsequent staining with Hoechst (nucleus, blue). The SPAAC condition bacteria were remodeled with the DBCO-488 (bacteria, green) and then invaded into the THP-1 cells. The cells were then fixed and stained with Hoechst (nucleus, blue). The 2D samples (B) were also stained with Phalloidin-TRITC (F-actin, purple). Images were taken on a Zeiss LSM800 Confocal Microscope with single plain snaps for 2D images and ortho-projections (XYZ) of Z-stacks of the cells in the synthetic hydrogels. Images are representative of a minimum of three fields viewed per replicate with at least two technical replicates, and experiments were conducted in at least three biological replicates. (B) Scale bars $=10 \mu \mathrm{m}$ (C) Scale bars $=5 \mu \mathrm{m}$.

label (Supplementary Figure S9). We suggest that this is due to the phagocytic and pinocytotic nature of macrophage cells to continuously sense their local environment for possible pathogens. We caution those culturing macrophages to find alternatives to DBCO dyes for fixed SPAAC staining.

\section{Cytokine Screen From Macrophages} Following Bacterial Invasion in 2D and 3D

Following successful invasion of macrophages in both 2D and 3D culture, we aimed to probe potential differences in cytokine expression as a measure of macrophage activation upon 


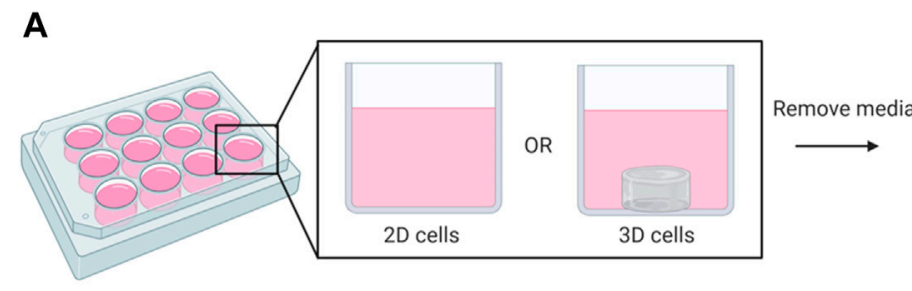

TNF-alpha

B

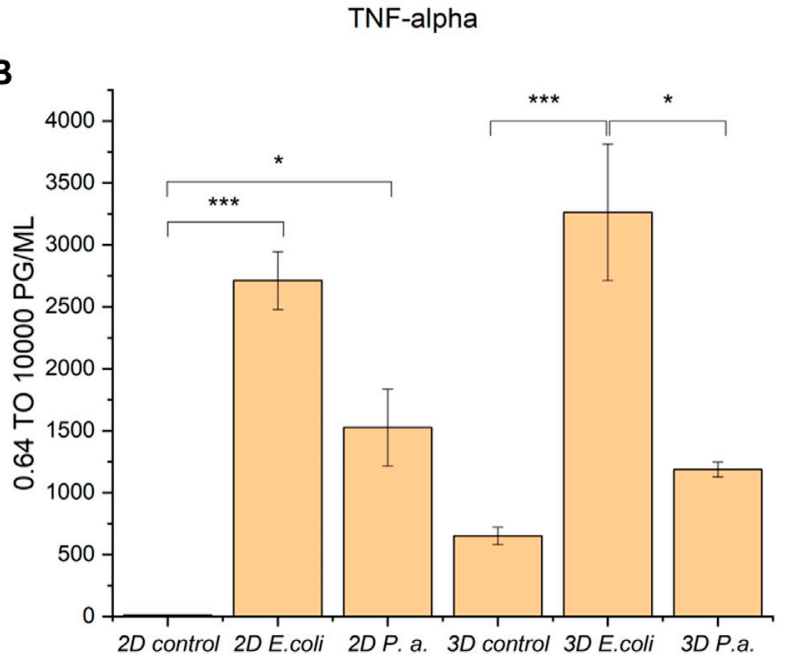

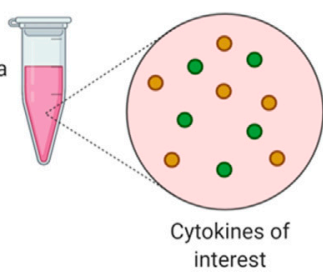

Prepare samples for ELISA analysis
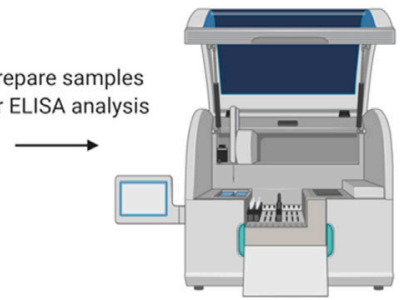

L-6

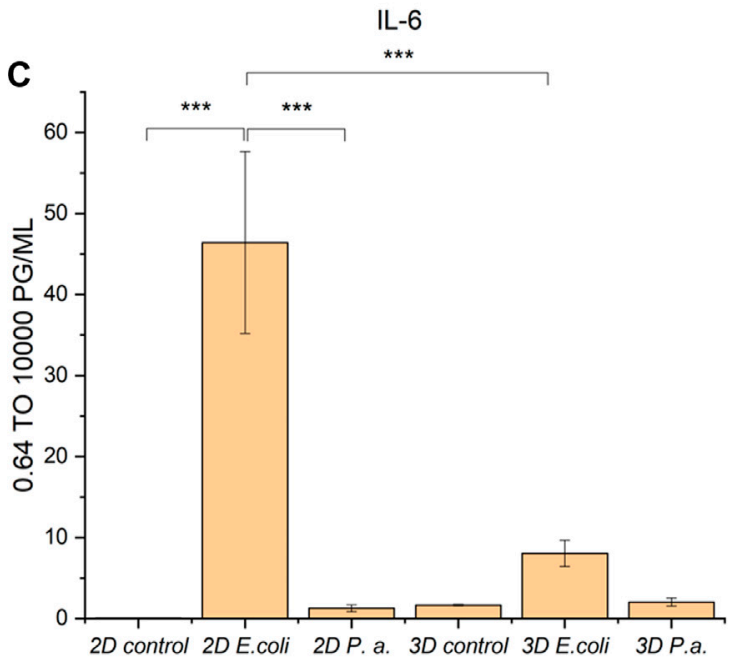

FIGURE 6 | ELISA analysis of TNF- $\alpha$ and IL-6 cytokine production by THP-1 macrophage cells in 2D and 3D culture upon invasion with E. coli or $P$. aeruginosa. (A) Macrophage cells in 2D or 3D culture were stimulated with bacteria or water for $4 \mathrm{~h}$. Cell culture supernatant was harvested and subjected to ELISA analysis for TNFalpha and IL-6 cytokines. (B) ELISA analysis of TNF-alpha shows cells stimulated with E. coli or P. aeruginosa exhibited increased secretion of TNF-alpha as compared to the control. (C) ELISA analysis of IL-6 shows cells stimulated with $E$. coli in 2D exhibited increased secretion of IL-6 as compared to in 3D culture and the controls. Macrophages in 2D and 3D culture when stimulated with $P$. aeruginosa did not exhibit increased secretion of IL-6 as compared to the control. All samples were analyzed in biological triplicate and technical duplicate and statistically analyzed by ANOVA with Tukey's test $\left({ }^{\star} p<0.05,{ }^{\star \star} p<0.01,{ }^{\star \star \star} p<0.001\right)$.

invasion, which may be influenced by the dimensionality and complexity of the culture system. Here, we utilized EQKU and $P$. aeruginosa, both unmodified. To assess macrophage response, we examined secretion of cytokines associated with different aspects of macrophage activation. Specifically, an enzyme-linked immunosorbent assay (ELISA) was implemented to observe cytokine output of tumor necrosis factor alpha (TNF- $\alpha$ ) and interleukin 6 (IL-6) of cells treated with E. coli, P. aeruginosa, or no bacteria. TNF- $\alpha$ is a cytokine involved in systemic inflammation and regulates immune cells, induces fever, inhibits viral replication, and induces apoptosis. Dysregulation of TNF- $\alpha$ is implicated in various diseases including IBD. IL- 6 is a cytokine involved in stem cell differentiation, antibody synthesis by B cells, and T cell cytotoxicity (Sanceau et al., 1991). IL-6 is produced in response to bacterial and viral infections, and work has shown that dysregulation of IL-6 can be involved in autoimmune disease pathogenesis (Sanceau et al., 1991).

When macrophages were invaded with either $E$. coli or $P$. aeruginosa, an increase in TNF- $\alpha$ expression was observed, which accurately represents known responses that THP-1 macrophages have to lipopolysaccharide (LPS) located on Gram-negative bacteria (Figure 6) (Zhang et al., 2008; Schildberger et al., 2013). Further, THP-1 macrophage cells from 2D plates treated with E. coli showed statistically significant increased expression of IL-6 as compared to untreated cells and cells treated with $P$. aeruginosa. Notably, THP-1 macrophage cells treated with $E$. coli in $3 \mathrm{D}$ culture did not show statistically different expression of IL-6 compared to the control and $P$. aeruginosa samples (Figure 6). These data suggest that the $3 \mathrm{D}$ invasion model produced a more biologically relevant response of IL- 6 to the various bacterial species, as literature precedent shows THP-1 macrophages treated with LPS are known to have little IL6 response (Schildberger et al., 2013).

\section{CONCLUSION}

Overall, we have established a well-defined hydrogel-based system for the $3 \mathrm{D}$ culture of monocytes and macrophages in an environment that mimics aspects of the basement membrane of the gut, and a multi-dimensional invasion assay for probing macrophage response to invading bacterial species. The multiscale system allows the integration of probes within the bacterial cell wall at the molecular level, control of bacterial-host interactions at the cellular level, and mimicry of aspects of the ECM 
dimensionality, biochemical content, and biophysical properties at the multi-cellular to tissue level initially and over time. This molecularly engineered system is reproducible, robust, and based on the underlying design of the synthetic matrix, provides future opportunities for not only probing the impacts of host-bacterial cell interactions, but also cell-matrix interactions through manipulation of extracellular biochemical and mechanical cues. The system is amenable to bioorthogonal chemistry on bacterial peptidoglycan within the hydrogel and opens the door for further applications in chemical biology involving labeling and study of the bacterial cell wall. This model system can be easily tailored for studying cell-cell and cell-matrix interactions in disease progression and for asking new questions beyond traditional $2 \mathrm{D}$ culturing methods that prevail in the field. The use of the NAM probes with the azide bioorthogonal handle embedded in the bacterial peptidoglycan allows for multiple click chemistry to take place, including $\mathrm{CuAAC}$ and SPAAC, and will provide opportunities to enrich for biologically produced bacterial cell wall fragments from these invasion systems for further analysis. These studies provide new insights into the interactions between bacteria and immune cells, and this new chemical biology model system provides a platform to examine how our immune system recognizes bacteria in a variety of physiologically relevant settings, including pathogen invasion and homeostatic maintenance.

\section{DATA AVAILABILITY STATEMENT}

The raw data supporting the conclusion of this article will be made available by the authors, without undue reservation.

\section{AUTHOR CONTRIBUTIONS}

KW, AK, and CG designed experiments. KW conducted experiments with assistance from JC for live cell imaging studies. KW, JC, AK, and CG analyzed data, prepared figures, and wrote and edited the manuscript. AK and CG supervised the studies.

\section{REFERENCES}

Ahmad, N., Colak, B., Zhang, D.-W., Gibbs, M. J., Watkinson, M., Becer, C. R., et al. (2019). Peptide Cross-Linked Poly (Ethylene Glycol) Hydrogel Films as Biosensor Coatings for the Detection of Collagenase. Sensors 19 (7), 1677. doi:10.3390/s19071677

Banahene, N., Kavunja, H. W., and Swarts, B. M. (2021). Chemical Reporters for Bacterial Glycans: Development and Applications. Chem. Rev. doi:10.1021/acs. chemrev.1c00729

Baskin, J. M., Prescher, J. A., Laughlin, S. T., Agard, N. J., Chang, P. V., Miller, I. A., et al. (2007). Copper-free Click Chemistry for Dynamic In Vivo Imaging. Proc. Natl. Acad. Sci. 104 (43), 16793-16797. doi:10.1073/pnas.0707090104

Benoit, D. S. W., Schwartz, M. P., Durney, A. R., and Anseth, K. S. (2008). Small Functional Groups for Controlled Differentiation of Hydrogel-Encapsulated

\section{FUNDING}

We are thankful for support from the Delaware COBRE program, supported by a grant from the National Institute of General Medical Sciences (NIGMS 1 P30 GM110758 and 1 P20 GM104316-01A1). Microscopy access was supported by the Delaware INBRE program, with a grant from NIGMS (P20 GM103446) and the State of Delaware. This research was supported by grants for related work from the NIH U01 Common Fund program with grant number U01CA221230-01 (CG) and the NIH Director's New Innovator Award with grant number DP2HL152424 (AK). KW would also like to thank the $\mathrm{NIH}$ for support through Chemistry-Biology Interface (CBI) training grant, T32GM133395. The authors acknowledge the use of facilities and instrumentation supported by NSF through the University of Delaware Materials Research Science and Engineering Center DMR-2011824.

\section{ACKNOWLEDGMENTS}

We thank Lisa Hester, and the University of Maryland Cytokine Core Laboratory, for assistance with ELISA assays. We thank Dr. Catherine Fromen and graduate student Bader Jarai for access and training on flow cytometry. KW would like to thank Dr. Lina Pradhan for initial training and mentorship for hydrogel chemistry and Dr. Kristen DeMeester for initial training and mentorship for bacteria labeling and mammalian cell culture. We would like to thank Liam-Michael Sandles for assistance with the DBCO plate reader assay and Samantha Cassel for culture of the CCL151 fibroblast cells. We would like to thank Cinta Santiago for synthesizing the AzNAM probe. We would like to thank Elizabeth D'Ambrosio and Samantha Cassel for critical reading of this manuscript. Figure 1 and Figure 6 were created using BioRender.com.

\section{SUPPLEMENTARY MATERIAL}

The Supplementary Material for this article can be found online at: https://www.frontiersin.org/articles/10.3389/fchem.2022.842602/ full\#supplementary-material

Human Mesenchymal Stem Cells. Nat. Mater 7 (10), 816-823. doi:10.1038/ nmat 2269

Blakney, A. K., Swartzlander, M. D., and Bryant, S. J. (2012). Student Award winner in the Undergraduate Category for the Society of Biomaterials 9th World Biomaterials Congress, Chengdu, China, June 1-5, 2012. J. Biomed. Mater. Res. 100A (6), 1375-1386. doi:10.1002/jbm.a.34104

Blasioli, D. J., Matthews, G. L., and Kaplan, D. L. (2014). The Degradation of Chondrogenic Pellets Using Cocultures of Synovial Fibroblasts and U937 Cells. Biomaterials 35 (4), 1185-1191. doi:10.1016/j.biomaterials.2013.10.050

Blumberg, R. S., Saubermann, L. J., and Strober, W. (1999). Animal Models of Mucosal Inflammation and Their Relation to Human Inflammatory Bowel Disease. Curr. Opin. Immunol. 11 (6), 648-656. doi:10.1016/s0952-7915(99) 00032-1

Brown, A. R., Wodzanowski, K. A., Santiago, C. C., Hyland, S. N., Follmar, J. L., Asare-Okai, P., et al. (2021). Protected N-Acetyl Muramic Acid Probes Improve 
Bacterial Peptidoglycan Incorporation via Metabolic Labeling. ACS Chem. Biol. 16 (10), 1908-1916. doi:10.1021/acschembio.1c00268

Brown, N. W., Jr., Shirley, J. D., Marshall, A. P., and Carlson, E. E. (2021). Comparison of Bioorthogonal $\beta$-Lactone Activity-Based Probes for Selective Labeling of Penicillin-Binding Proteins. Chembiochem 22 (1), 193-202. doi:10. 1002/cbic. 202000556

Bryant, S. J., Nuttelman, C. R., and Anseth, K. S. (2000). Cytocompatibility of UV and Visible Light Photoinitiating Systems on Cultured NIH/3T3 Fibroblasts In Vitro. J. Biomater. Sci. Polym. Edition 11 (5), 439-457. doi:10.1163/ 156856200743805

Caliari, S. R., and Burdick, J. A. (2016). A Practical Guide to Hydrogels for Cell Culture. Nat. Methods 13 (5), 405-414. doi:10.1038/nmeth.3839

Chang, P. V., Prescher, J. A., Sletten, E. M., Baskin, J. M., Miller, I. A., Agard, N. J., et al. (2010). Copper-free Click Chemistry in Living Animals. Proc. Natl. Acad. Sci. USA 107 (5), 1821-1826. doi:10.1073/pnas.0911116107

Chellat, F., Grandjean-Laquerriere, A., Naour, R. L., Fernandes, J., Yahia, L. H., Guenounou, M., et al. (2005). Metalloproteinase and Cytokine Production by THP-1 Macrophages Following Exposure to Chitosan-DNA Nanoparticles. Biomaterials 26 (9), 961-970. doi:10.1016/j.biomaterials.2004.04.006

Clevers, H. (2016). Modeling Development and Disease with Organoids. Cell 165 (7), 1586-1597. doi:10.1016/j.cell.2016.05.082

Daigneault, M., Preston, J. A., Marriott, H. M., Whyte, M. K. B., and Dockrell, D. H. (2010). The Identification of Markers of Macrophage Differentiation in PMAStimulated THP-1 Cells and Monocyte-Derived Macrophages. PLoS One 5 (1), e8668. doi:10.1371/journal.pone. 0008668

de Souza, N. (2018). A Model Gut Microbiome. Nat. Methods 15 (8), 572. doi:10. 1038/s41592-018-0094-z

Debets, M. F., Tastan, O. Y., Wisnovsky, S. P., Malaker, S. A., Angelis, N., Moeckl, L. K. R., et al. (2020). Metabolic Precision Labeling Enables Selective Probing of O-linkedN-Acetylgalactosamine Glycosylation. Proc. Natl. Acad. Sci. USA 117 (41), 25293-25301. doi:10.1073/pnas.2007297117

DeMeester, K. E., Liang, H., Zhou, J., Wodzanowski, K. A., Prather, B. L., Santiago, C. C., et al. (2019). Metabolic Incorporation of N-Acetyl Muramic Acid Probes into Bacterial Peptidoglycan. Curr. Protoc. Chem. Biol. 11 (4), e74. doi:10.1002/ cpch.74

DeMeester, K. E., Liang, H., Jensen, M. R., Jones, Z. S., D’Ambrosio, E. A., Scinto, S. L., et al. (2018). Synthesis of Functionalized N-Acetyl Muramic Acids to Probe Bacterial Cell Wall Recycling and Biosynthesis. J. Am. Chem. Soc. 140 (30), 9458-9465. doi:10.1021/jacs.8b03304

Zhang, D., Chen, L., Li, S., Gu, Z., and Yan, J. (2008). Lipopolysaccharide (LPS) of Porphyromonas Gingivalis Induces IL- $1 \beta$, TNF- $\alpha$ and IL-6 Production by THP-1 Cells in a Way Different from that of Escherichia coli LPS. Innate Immun. 14 (2), 99-107. doi:10.1177/1753425907088244

Ei-Hajj, Z. W., and Newman, E. B. (2015). How Much Territory Can a Single E-Coli Cell Control? Front. Microbiol. 6.

Engler, A. J., Sen, S., Sweeney, H. L., and Discher, D. E. (2006). Matrix Elasticity Directs Stem Cell Lineage Specification. Cell 126 (4), 677-689. doi:10.1016/j. cell.2006.06.044

Fairbanks, B. D., Schwartz, M. P., Halevi, A. E., Nuttelman, C. R., Bowman, C. N., and Anseth, K. S. (2009). A Versatile Synthetic Extracellular Matrix Mimic via Thiol-Norbornene Photopolymerization. Adv. Mater. 21 (48), 5005-5010. doi:10.1002/adma.200901808

Galli, S. J., Borregaard, N., and Wynn, T. A. (2011). Phenotypic and Functional Plasticity of Cells of Innate Immunity: Macrophages, Mast Cells and Neutrophils. Nat. Immunol. 12 (11), 1035-1044. doi:10.1038/ni.2109

Geddes, K., Magalhães, J. G., and Girardin, S. E. (2009). Unleashing the Therapeutic Potential of NOD-like Receptors. Nat. Rev. Drug Discov. 8 (6), 465-479. doi:10.1038/nrd2783

Gerecht, S., Burdick, J. A., Ferreira, L. S., Townsend, S. A., Langer, R., and VunjakNovakovic, G. (2007). Hyaluronic Acid Hydrogel for Controlled Self-Renewal and Differentiation of Human Embryonic Stem Cells. Proc. Natl. Acad. Sci. 104 (27), 11298-11303. doi:10.1073/pnas.0703723104

Gisin, J., Schneider, A., Nägele, B., Borisova, M., and Mayer, C. (2013). A Cell wall Recycling Shortcut that Bypasses Peptidoglycan De Novo Biosynthesis. Nat. Chem. Biol. 9 (8), 491-493. doi:10.1038/nchembio.1289

Goyal, N., Rana, A., Ahlawat, A., Bijjem, K. R. V., and Kumar, P. (2014). Animal Models of Inflammatory Bowel Disease: a Review. Inflammopharmacol 22 (4), 219-233. doi:10.1007/s10787-014-0207-y
Hasegawa, M., Yang, K., Hashimoto, M., Park, J.-H., Kim, Y.-G., Fujimoto, Y., et al. (2006). Differential Release and Distribution of Nod1 and Nod2 Immunostimulatory Molecules Among Bacterial Species and Environments. J. Biol. Chem. 281 (39), 29054-29063. doi:10.1074/jbc. m602638200

Herskovits, A. A., Auerbuch, V., and Portnoy, D. A. (2007). Bacterial Ligands Generated in a Phagosome Are Targets of the Cytosolic Innate Immune System. Plos Pathog. 3 (3), e51. doi:10.1371/journal.ppat.0030051

Humann, J., and Lenz, L. L. (2009). Bacterial Peptidoglycan-Degrading Enzymes and Their Impact on Host Muropeptide Detection. J. Innate Immun. 1 (2), 88-97. doi:10.1159/000181181

Italiani, P., and Boraschi, D. (2014). From Monocytes to M1/M2 Macrophages: Phenotypical vs. Functional Differentiation. Front. Immunol. 5, 514. doi:10. 3389/fimmu.2014.00514

Johnson, L. A., Rodansky, E. S., Sauder, K. L., Horowitz, J. C., Mih, J. D., Tschumperlin, D. J., et al. (2013). Matrix Stiffness Corresponding to Strictured Bowel Induces a Fibrogenic Response in Human Colonic Fibroblasts. Inflamm. Bowel Dis. 19 (5), 891-903. doi:10.1097/mib. 0b013e3182813297

Johnston, R. B., Jr. (1988). Monocytes and Macrophages. N. Engl. J. Med. 318 (12), 747-752. doi:10.1056/nejm198803243181205

Jowett, G. M., Norman, M. D. A., Yu, T. T. L., Rosell Arévalo, P., Hoogland, D., Lust, S. T., et al. (2021). ILC1 Drive Intestinal Epithelial and Matrix Remodelling. Nat. Mater. 20 (2), 250-259. doi:10.1038/s41563-020-0783-8

Kahan, F. M., Kahan, J. S., Cassidy, P. J., and Kropp, H. (1974). The Mechanism of Action of Fosfomycin (Phosphonomycin). Ann. N. Y Acad. Sci. 235 (0), 364-386. doi:10.1111/j.1749-6632.1974.tb43277.x

Kim, M., Lee, S., and Ki, C. S. (2019). Cellular Behavior of RAW264.7 Cells in 3D Poly(ethylene Glycol) Hydrogel Niches. ACS Biomater. Sci. Eng. 5 (2), 922-932. doi:10.1021/acsbiomaterials.8b01150

Liang, H., DeMeester, K. E., Hou, C.-W., Parent, M. A., Caplan, J. L., and Grimes, C. L. (2017). Metabolic Labelling of the Carbohydrate Core in Bacterial Peptidoglycan and its Applications. Nat. Commun. 8, 15015. doi:10.1038/ ncomms 15015

Lister, P. D., Wolter, D. J., and Hanson, N. D. (2009). Antibacterial-Resistant Pseudomonas aeruginosa : Clinical Impact and Complex Regulation of Chromosomally Encoded Resistance Mechanisms. Clin. Microbiol. Rev. 22 (4), 582-610. doi:10.1128/cmr.00040-09

Loebel, C., Mauck, R. L., and Burdick, J. A. (2019). Local Nascent Protein Deposition and Remodelling Guide Mesenchymal Stromal Cell Mechanosensing and Fate in Three-Dimensional Hydrogels. Nat. Mater. 18 (8), 883-891. doi:10.1038/s41563-019-0307-6

Lund, M. E., To, J., O'Brien, B. A., and Donnelly, S. (2016). The Choice of Phorbol 12-myristate 13-acetate Differentiation Protocol Influences the Response of THP-1 Macrophages to a Pro-inflammatory Stimulus. J. Immunological Methods 430, 64-70. doi:10.1016/j.jim.2016.01.012

Macdougall, L. J., Wiley, K. L., Kloxin, A. M., and Dove, A. P. (2018). Design of Synthetic Extracellular Matrices for Probing Breast Cancer Cell Growth Using Robust Cyctocompatible Nucleophilic Thiol-Yne Addition Chemistry. Biomaterials 178, 435-447. doi:10.1016/j.biomaterials.2018.04.046

Medzhitov, R. (2021). The Spectrum of Inflammatory Responses. Science 374 (6571), 1070-1075. doi:10.1126/science.abi5200

Montefusco-Pereira, C. V., Horstmann, J. C., Ebensen, T., Beisswenger, C., Bals, R., Guzman, C. A., et al. (2020). P. aeruginosa Infected 3D Co-culture of Bronchial Epithelial Cells and Macrophages at Air-Liquid Interface for Preclinical Evaluation of Anti-infectives. J. Vis. Exp. 160, e61069. doi:10.3791/61069

Mountcastle, S. E., Cox, S. C., Sammons, R. L., Jabbari, S., Shelton, R. M., and Kuehne, S. A. (2020). A Review of Co-culture Models to Study the Oral Microenvironment and Disease. J. Oral Microbiol. 12 (1), 1773122. doi:10. 1080/20002297.2020.1773122

Neef, A. B., and Schultz, C. (2009). Selective Fluorescence Labeling of Lipids in Living Cells. Angew. Chem. Int. Ed. 48 (8), 1498-1500. doi:10.1002/anie. 200805507

Nikić, I., Kang, J. H., Girona, G. E., Aramburu, I. V., and Lemke, E. A. (2015). Labeling Proteins on Live Mammalian Cells Using Click Chemistry. Nat. Protoc. 10 (5), 780-791. doi:10.1038/nprot.2015.045

Ovadia, E. M., Colby, D. W., and Kloxin, A. M. (2018). Designing Well-Defined Photopolymerized Synthetic Matrices for Three-Dimensional Culture and 
Differentiation of Induced Pluripotent Stem Cells. Biomater. Sci. 6 (6), 1358-1370. doi:10.1039/c8bm00099a

Peck, Y., Ng, L. Y., Goh, J. Y. L., Gao, C., and Wang, D.-A. (2014). A ThreeDimensionally Engineered Biomimetic Cartilaginous Tissue Model for Osteoarthritic Drug Evaluation. Mol. Pharmaceutics 11 (7), 1997-2008. doi:10.1021/mp500026x

Petersen, O. W., Ronnov-Jessen, L., Howlett, A. R., and Bissell, M. J. (1992). Interaction with Basement Membrane Serves to Rapidly Distinguish Growth and Differentiation Pattern of normal and Malignant Human Breast Epithelial Cells. Proc. Natl. Acad. Sci. 89 (19), 9064-9068. doi:10.1073/pnas.89.19.9064

Rehmann, M. S., and Kloxin, A. M. (2013). Tunable and Dynamic Soft Materials for Three-Dimensional Cell Culture. Soft Matter 9 (29), 6737-6746. doi:10. 1039/c3sm50217a

Rehmann, M. S., Luna, J. I., Maverakis, E., and Kloxin, A. M. (2016). Tuning Microenvironment Modulus and Biochemical Composition Promotes Human Mesenchymal Stem Cell Tenogenic Differentiation. J. Biomed. Mater. Res. 104 (5), 1162-1174. doi:10.1002/jbm.a.35650

Rezakhani, S., Gjorevski, N., and Lutolf, M. P. (2021). Extracellular Matrix Requirements for Gastrointestinal Organoid Cultures. Biomaterials 276, 121020. doi:10.1016/j.biomaterials.2021.121020

Samavedi, S., Diaz-Rodriguez, P., Erndt-Marino, J. D., and Hahn, M. S. (2017). A Three-Dimensional Chondrocyte-Macrophage Coculture System to Probe Inflammation in Experimental Osteoarthritis. Tissue Eng. Part. A. 23 (3-4), 101-114. doi:10.1089/ten.TEA.2016.0007

Sanceau, J., Wijdenes, J., Revel, M., and Wietzerbin, J. (1991). IL-6 and IL-6 Receptor Modulation by IFN-Gamma and Tumor Necrosis Factor-Alpha in Human Monocytic Cell Line (THP-1). Priming Effect of IFN-Gamma. J. Immunol. 147 (8), 2630-2637.

Schildberger, A., Rossmanith, E., Eichhorn, T., Strassl, K., and Weber, V. (2013). Monocytes, Peripheral Blood Mononuclear Cells, and THP-1 Cells Exhibit Different Cytokine Expression Patterns Following Stimulation with Lipopolysaccharide. Mediators Inflamm. 2013, 697972. doi:10.1155/2013/697972

Simon-Assmann, P., Kedinger, M., De Arcangelis, A., Rousseau, V., and Simo, P. (1995). Extracellular Matrix Components in Intestinal Development. Experientia 51 (9-10), 883-900. doi:10.1007/BF01921739

Smithmyer, M. E., Sawicki, L. A., and Kloxin, A. M. (2014). Hydrogel Scaffolds Asin Vitromodels to Study Fibroblast Activation in Wound Healing and Disease. Biomater. Sci. 2 (5), 634-650. doi:10.1039/c3bm60319a

Snyder, J., Wang, C.-M., Zhang, A. Q., Li, Y., Luchan, J., Hosic, S., et al. (2020). Materials and Microenvironments for Engineering the Intestinal Epithelium. Ann. Biomed. Eng. 48 (7), 1916-1940. doi:10.1007/s10439-020-02470-8

Sun, L., Wang, X., and Kaplan, D. L. (2011). A 3D Cartilage - Inflammatory Cell Culture System for the Modeling of Human Osteoarthritis. Biomaterials 32 (24), 5581-5589. doi:10.1016/j.biomaterials.2011.04.028

Tanaka, H., Murphy, C. L., Murphy, C., Kimura, M., Kawai, S., and Polak, J. M. (2004). Chondrogenic Differentiation of Murine Embryonic Stem Cells: Effects of Culture Conditions and Dexamethasone. J. Cel. Biochem. 93 (3), 454-462. doi:10.1002/jcb.20171

Taylor, J. A., Bratton, B. P., Sichel, S. R., Blair, K. M., Jacobs, H. M., DeMeester, K. E., et al. (2020). Distinct Cytoskeletal Proteins Define Zones of Enhanced Cell wall Synthesis in Helicobacter pylori. Elife 9, e52482. doi:10.7554/eLife.52482
Taylor, J. A., Santiago, C. C., Gray, J., Wodzanowski, K. A., DeMeester, K. E. Biboy, J., et al. (2021). Localizing Peptidoglycan Synthesis in Helicobacter pylori Using Clickable Metabolic Probes. Curr. Protoc. 1 (4), e80. doi:10. 1002/cpz1.80

Thaiss, C. A., Zmora, N., Levy, M., and Elinav, E. (2016). The Microbiome and Innate Immunity. Nature 535 (7610), 65-74. doi:10.1038/nature18847

Tibbitt, M. W., and Anseth, K. S. (2009). Hydrogels as Extracellular Matrix Mimics for 3D Cell Culture. Biotechnol. Bioeng. 103 (4), 655-663. doi:10. 1002/bit.22361

Wang, D., Zhang, Y., and Kleiner, R. E. (2020). Cell- and Polymerase-Selective Metabolic Labeling of Cellular RNA with 2'-Azidocytidine. J. Am. Chem. Soc. 142 (34), 14417-14421. doi:10.1021/jacs.0c04566

Webb, D. R. (2014). Animal Models of Human Disease: Inflammation. Biochem. Pharmacol. 87 (1), 121-130. doi:10.1016/j.bcp.2013.06.014

Williams, C. G., Malik, A. N., Kim, T. K., Manson, P. N., and Elisseeff, J. H. (2005). Variable Cytocompatibility of Six Cell Lines with Photoinitiators Used for Polymerizing Hydrogels and Cell Encapsulation. Biomaterials 26 (11), 1211-1218. doi:10.1016/j.biomaterials.2004.04.024

Witherel, C. E., Abebayehu, D., Barker, T. H., and Spiller, K. L. (2019). Macrophage and Fibroblast Interactions in Biomaterial-Mediated Fibrosis. Adv. Healthc Mater. 8 (4), e1801451. doi:10.1002/adhm.201801451

Wodzanowski, K. A., Cassel, S. E., Grimes, C. L., and Kloxin, A. M. (2020). Tools for Probing Host-Bacteria Interactions in the Gut Microenvironment: From Molecular to Cellular Levels. Bioorg. Med. Chem. Lett. 30 (10), 127116. doi:10. 1016/j.bmcl.2020.127116

Yamada, Y., Hozumi, K., and Nomizu, M. (2011). Construction and Activity of a Synthetic Basement Membrane with Active Laminin Peptides and Polysaccharides. Chem. Eur. J. 17 (38), 10500-10508. doi:10.1002/chem. 201101064

Zeng, B. N., Cai, Z. L., Lalevee, J., Yang, Q. Z., Lai, H. W., Xiao, P., et al. (2021). Cytotoxic and Cytocompatible Comparison Among Seven PhotoinitiatorsTriggered Polymers in Different Tissue Cells. Toxicol. Vitro 72, 105103. doi:10.1016/j.tiv.2021.105103

Conflict of Interest: The authors declare that the research was conducted in the absence of any commercial or financial relationships that could be construed as a potential conflict of interest.

Publisher's Note: All claims expressed in this article are solely those of the authors and do not necessarily represent those of their affiliated organizations, or those of the publisher, the editors, and the reviewers. Any product that may be evaluated in this article, or claim that may be made by its manufacturer, is not guaranteed or endorsed by the publisher.

Copyright $\odot 2022$ Wodzanowski, Caplan, Kloxin and Grimes. This is an open-access article distributed under the terms of the Creative Commons Attribution License (CC $B Y)$. The use, distribution or reproduction in other forums is permitted, provided the original author(s) and the copyright owner(s) are credited and that the original publication in this journal is cited, in accordance with accepted academic practice. No use, distribution or reproduction is permitted which does not comply with these terms. 